University of Nebraska - Lincoln

DigitalCommons@University of Nebraska - Lincoln

Publications, Agencies and Staff of the U.S.

Department of Commerce

U.S. Department of Commerce

2011

Cloud statistics and cloud radiative effect for a low-mountain site

\author{
Kerstin Ebell \\ University of Cologne, kebell@meteo.uni-koeln.de \\ Susanne Crewell \\ University of Cologne \\ Ulrich Löhnert \\ University of Cologne \\ David D. Turner \\ University of Wisconsin - Madison \\ Ewan J. O'Connor \\ University of Reading
}

Follow this and additional works at: https://digitalcommons.unl.edu/usdeptcommercepub

Part of the Environmental Sciences Commons

Ebell, Kerstin; Crewell, Susanne; Löhnert, Ulrich; Turner, David D.; and O'Connor, Ewan J., "Cloud statistics and cloud radiative effect for a low-mountain site" (2011). Publications, Agencies and Staff of the U.S. Department of Commerce. 258.

https://digitalcommons.unl.edu/usdeptcommercepub/258

This Article is brought to you for free and open access by the U.S. Department of Commerce at DigitalCommons@University of Nebraska - Lincoln. It has been accepted for inclusion in Publications, Agencies and Staff of the U.S. Department of Commerce by an authorized administrator of DigitalCommons@University of Nebraska - Lincoln. 


\title{
RMetS
}

\section{Cloud statistics and cloud radiative effect for a low-mountain site}

\author{
Kerstin Ebell, ${ }^{\mathrm{a} *}$ Susanne Crewell, ${ }^{\mathrm{a}}$ Ulrich Löhnert, ${ }^{\mathrm{a}}$ David D. Turner ${ }^{\mathrm{b}, \mathrm{c}}$ and Ewan J. \\ O'Connor ${ }^{\mathrm{d}, \mathrm{e}}$ \\ anstitute for Geophysics and Meteorology, University of Cologne, Germany \\ ${ }^{\mathrm{b}}$ University of Wisconsin-Madison, Madison, Wisconsin, USA \\ ${ }^{\mathrm{c}}$ NOAA / National Severe Storms Laboratory, Norman, Oklahoma, USA \\ ${ }^{\mathrm{d}}$ University of Reading, Reading, UK \\ ${ }^{\mathrm{e}}$ Finnish Meteorological Institute, Helsinki, Finland \\ ${ }^{\star}$ Correspondence to: K. Ebell, Institute for Geophysics and Meteorology University of Cologne Zuelpicher Str. 49a \\ Cologne 50674 Germany. E-mail: kebell@meteo.uni-koeln.de
}

\begin{abstract}
In 2007, the Atmospheric Radiation Measurement (ARM) Mobile Facility (AMF) was operated for a nine-month period in the Murg Valley, Black Forest, Germany, in support of the Convective and Orographically-induced Precipitation Study (COPS). The synergy of AMF and COPS partner instrumentation was exploited to derive a set of high-quality thermodynamic and cloud property profiles with $30 \mathrm{~s}$ resolution. In total, clouds were present $72 \%$ of the time, with multi-layer mixed phase $(28.4 \%)$ and single-layer water clouds $(11.3 \%)$ occurring most frequently. A comparison with the Cloudnet sites Chilbolton and Lindenberg for the same time period revealed that the Murg Valley exhibits lower liquid water paths (LWPs; median $=37.5 \mathrm{~g} \mathrm{~m}^{-2}$ ) compared to the two sites located in flat terrain. In order to evaluate the derived thermodynamic and cloud property profiles, a radiative closure study was performed with independent surface radiation measurements. In clear sky, average differences between calculated and observed surface fluxes are less than $2 \%$ and $4 \%$ for the short wave and long wave part, respectively. In cloudy situations, differences between simulated and observed fluxes, particularly in the short wave part, are much larger, but most of these can be related to broken cloud situations. The daytime cloud radiative effect (CRE), i.e. the difference of cloudy and clear-sky net fluxes, has been analysed for the whole nine-month period. For overcast, single-layer water clouds, sensitivity studies revealed that the CRE uncertainty is likewise determined by uncertainties in liquid water content and effective radius. For low LWP clouds, CRE uncertainty is dominated by LWP uncertainty; therefore refined retrievals, such as using infrared and/or higher microwave frequencies, are needed. Copyright (c) 2011 Royal Meteorological Society
\end{abstract}

\footnotetext{
Key Words: clouds; radiation; remote sensing

Received 26 February 2010; Revised 26 October 2010; Accepted 22 November 2010; Published online in Wiley Online Library 9 February 2011

Citation: Ebell K, Crewell S, Löhnert U, Turner DD, O'Connor EJ. 2011. Cloud statistics and cloud radiative effect for a low-mountain site. Q. J. R. Meteorol. Soc. 137: 306-324. DOI:10.1002/qj.748
}

\section{Introduction}

Clouds and their interaction with radiation still pose the single largest source of uncertainty in future-climate projections (IPCC, 2007). Part of the reason is the limited knowledge of cloud macro- and microphysical statistics in connection to their effect on the radiative budget. The cloud radiative effect (CRE) is defined as the difference 
between all-sky and clear-sky irradiances. Because the latter are the irradiances that one would measure if the cloud were not present, they need to either be estimated (Long and Ackerman, 2000) from observations or determined by a radiative transfer model. Short wave (SW) CRE is mostly negative due to the strong scattering of cloud particles, with highest values for stratocumulus clouds (Chen et al., 2000). In the long wave (LW) part, cloud absorption of upwelling radiation generally leads to positive CRE. SW and LW CRE at the surface (SFC), in the atmosphere (ATM), and top of the atmosphere (TOA) vary strongly depending on cloud macroscopic and microscopic properties. Therefore, net CRE as the difference of two large and variable values is difficult to determine, and in particular its development in a changing climate is highly uncertain (Norris and Slingo, 2009).

In order to better understand and eventually predict CRE, more detailed observations are urgently needed (Norris and Slingo, 2009). Today, the most accurate estimates of vertically resolved cloud properties and corresponding surface irradiances can be gained from the synergy of ground-based instruments including at least cloud radar, lidar, microwave radiometer and radiation sensors. Such instrumentation is operated only at a few anchor sites worldwide, such as the three permanent and two mobile facilities of the Atmospheric Radiation Measurement programme (ARM: Ackerman and Stokes, 2003) and those organized in the Cloudnet programme (Illingworth et al., 2007), i.e. Cabauw, Chilbolton, SIRTA (Site Instrumental de Recherche par Télédétection Atmosphérique) at Palaiseau, and Lindenberg. These sites are particularly valuable in observing low altitude clouds, which are difficult to capture by satellite instrumentation. Observations from these sites, which are all located in relatively flat terrain, have been used to investigate the representation of clouds in numerical weather prediction (NWP) (e.g. Hogan et al., 2009), regional (e.g. Willén et al., 2005) and global (Zhang et al., 2005) climate models.

For analysing cloud radiation interaction, Mather et al. (2007) compiled a dataset of thermodynamic and cloud property profiles using ARM observations at the tropical western Pacific islands Manus and Nauru. On the basis of these profiles, they calculated radiative fluxes and heating rates and found a net warming of high and midlevel clouds. At Nauru, boundary layer clouds prevailed with a cooling effect in and above the cloud layer and a net warming below. In a sequel study, Mather and McFarlane (2009) analysed radiative heating rate profiles with respect to different cloud classes occurring at both tropical sites. Mace et al. (2006a, 2006b) performed a statistical analysis of long-term cloud properties from one year of vertically resolved observations at the ARM Southern Great Plains (SGP) Central Facility. They derived the CRE of SW and LW irradiances as a function of cloud type, and found that the predominant surface CREs are associated with thin cirrus cloud layers and thick low-level clouds, due in part to their very frequent occurrence compared to other types of cloud. Dupont and Haeffelin (2008) used observations from the French Cloudnet site SIRTA in Palaiseau to develop parametrizations for cirrus cloud CRE in SW and LW.

Several studies using ARM data attempted to identify the dominant drivers for CRE. Dong et al. $(2005,2006)$ show on the basis of five years of SGP data that SW CRE is driven by solar zenith angle and cloud hydrometeors while water vapour changes are most important for the LW CRE. Similar studies have also investigated the role of surface albedo on the CRE at other sites (e.g. Shupe and Intrieri, 2004). The radiative impact of water clouds depends on two microphysical quantities, i.e. liquid water path (LWP) and effective radius $\left(r_{\text {eff }}\right)$. Sengupta et al. (2003) assessed the relative importance of accurate LWP and $r_{\text {eff }}$ observations to accurately describe SW CRE at the surface. Considering selected episodes of overcast boundary layer stratocumulus clouds they find a higher sensitivity of solar flux to LWP compared to $r_{\text {eff }}$.

From 1 April to 31 December 2007 the ARM Mobile Facility (AMF) was deployed in the Murg Valley, Black Forest, Germany (48 $38^{\circ} 24.18^{\prime \prime} \mathrm{N}, 8^{\circ} 23^{\prime} 48.72^{\prime \prime} \mathrm{E}$, altitude: $511.43 \mathrm{~m}$ above mean sea level (MSL)). The AMF was augmented and extended as part of the Convective and Orographically-induced Precipitation Study (COPS) experiment (Wulfmeyer et al., 2008, 2011) by the collocation of additional instrumentation: two microwave radiometers, aerosol and Doppler wind lidars, a 'microrain' precipitation radar, Global Positioning System (GPS) receiver, and soil moisture sensors. The valley, which is roughly one kilometre wide, is oriented in the north-south direction with ridges rising more than $300 \mathrm{~m}$ on both sides of the valley.

Since all other observational sites mentioned above are located in flat terrain, this set-up provides the first opportunity to study clouds and their radiative effects in a low-mountain terrain. The Black Forest region has a typical midlatitude moderate climate and is mainly under the influence of westerly flow and anticyclonic situations. In the summertime, cloud and precipitation formation are often driven by convective processes. In general, the development of clouds in low-mountain regions is simultaneously influenced by mesoscale and synoptic scale systems, landsurface processes and the orography. The north-south orientation of the Murg Valley and the prevailing westerly flow and anticyclonal situations in southern Germany might influence the cloud fields in the Murg Valley.

In this paper, we provide a statistical description of the clouds present above the AMF over its full deployment and characterize their radiative properties. For this purpose, a dataset containing all necessary information for radiative transfer calculations, i.e. thermodynamic profiles, cloud liquid and ice water content (LWC, IWC) and effective radius $\left(r_{\text {eff,liq }}, r_{\text {eff,ice }}\right)$, is generated (Figure 1 , section 2$)$. In this exercise, mean aerosol and albedo conditions are also derived. The occurrence of different cloud types, as well as the vertical hydrometeor distribution and mean microphysical properties, are statistically analysed. A radiative closure study is performed for clear and cloudy sky conditions to assess the quality of the dataset (section 4). For singlelayer water clouds, which occur rather frequently, the cloud radiative effect and its dependence on the uncertainties in the observations is investigated in detail (section 4.3). Finally, the results are summarized (section 5) and an outlook is given (section 6).

\section{Technique}

In order to study cloud radiation interactions, a realistic description of the atmospheric state, i.e. the thermodynamics as well as the cloud macrophysical, microphysical and radiative properties, is needed for the AMF site. For 


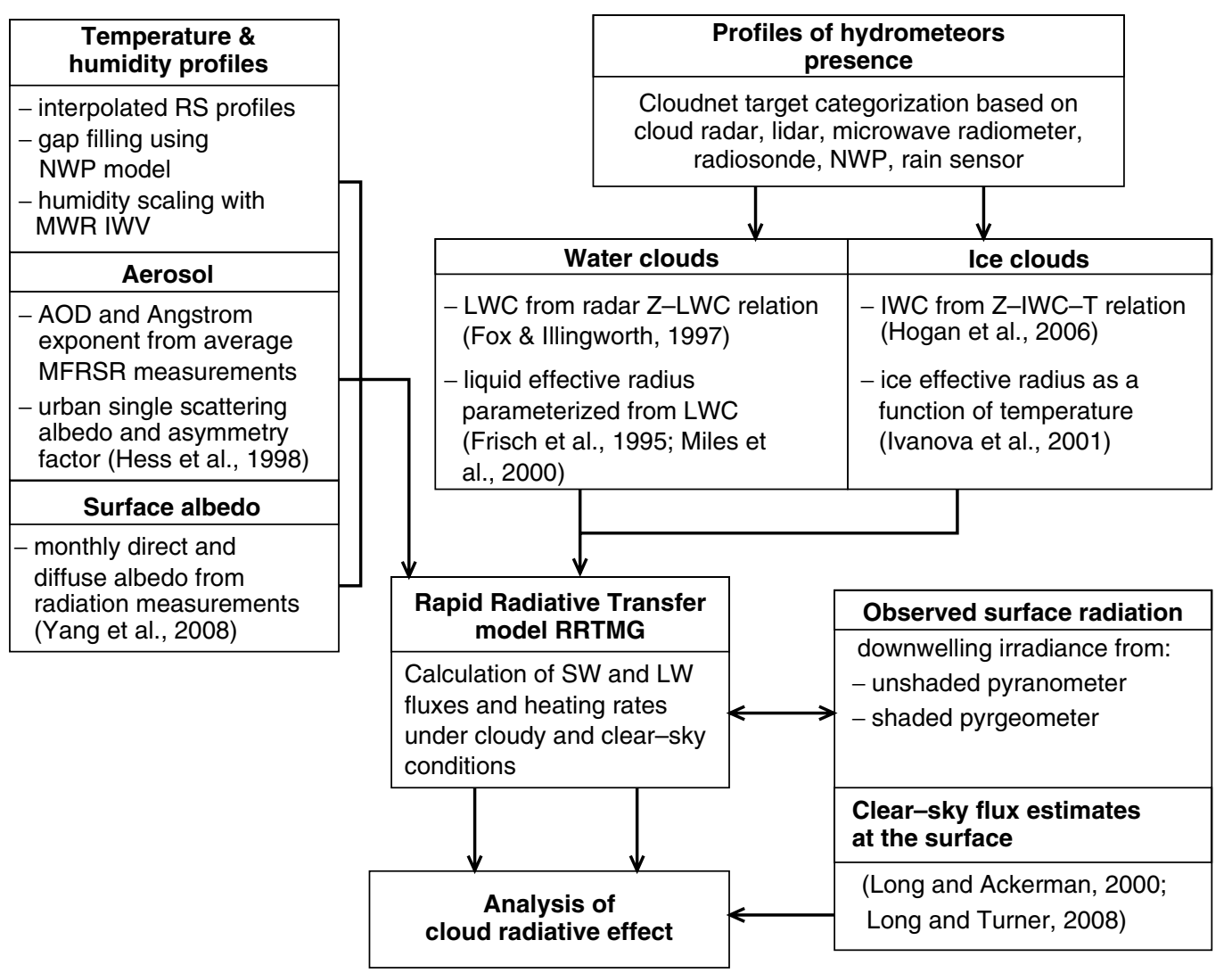

Figure 1. Overview of the retrieval and validation strategy.

the compilation of such a dataset, information from different active and passive remote-sensing instruments has to be merged into one data stream, which characterizes the atmospheric column best. The instruments used in this study encompass cloud radar, microwave radiometer, lidar, GPS and radiosondes, as well as surface instrumentation giving meteorological data. Key instruments to derive cloud properties are the vertically pointing AMF $95 \mathrm{GHz}$ cloud radar, the multi-channel microwave radiometer (MWR) HATPRO (Humidity And Temperature PROfiler: Rose et al., 2005) and the AMF two-channel MWR. The cloud radar reflectivity profile includes information on the vertical profile of cloud properties, while the MWR measures the integrated value of the liquid water content, i.e. the LWP. Thermodynamic profiles are mainly derived from radiosonde data.

The compilation of high-quality thermodynamic and cloud properties from multiple sensors and datasets is a demanding task. The datasets have to be spatially and temporally interpolated and care has to be taken that the thermodynamic and cloud profiles are consistent with each other. If one single measurement is missing or does not pass the quality checks, the whole profile might be excluded from the analysis. Although this procedure might significantly reduce the dataset, this is the only way to assure that the derived atmospheric state is reasonable.

In the following, the technique to derive the thermodynamic and cloud properties will be explained in detail. The different datasets and procedures are summarized in Figure 1 giving an overview of the sampling technique. The starting point in the data processing is the Cloudnet target categorization product (Illingworth et al., 2007), which identifies the presence of hydrometeor types for a temporal
( $\Delta t=30 \mathrm{~s})$ and vertical $(\Delta z=43 \mathrm{~m})$ grid. The same vertical and temporal resolution is used for the final dataset. The target categorization is the precondition to subsequently apply algorithms to derive cloud microphysical properties for the corresponding hydrometeor type. In the next section, the target categorization and the limits of this technique will be presented, followed by the characterization of the thermodynamic (section 2.2) and cloud property (section 2.3) profiles.

\subsection{Cloudnet target categorization}

The target categorization itself is a synergistic product of cloud radar, lidar (ceilometer), microwave radiometer, rain sensor, radiosonde and NWP model information (Illingworth et al., 2007). The basic principle is that the radar is sensitive to large particles such as rain and drizzle drops, ice particles and insects, while the lidar is sensitive to higher concentrations of smaller particles. Lidar backscatter and Doppler radar parameters are used to classify the targets as one of the following: (i) aerosols, (ii) insects, (iii) aerosols and insects, (iv) ice and supercooled droplets, (v) ice only, (vi) drizzle/rain and cloud droplets, (vii) drizzle or rain, (viii) cloud droplets only, and (ix) clear sky. Dual- or multiwavelength microwave radiometer data, and temperature profiles from radiosondes or operational NWP model output, are also required inputs. This objective method of target categorization has been shown to be robust (e.g. Protat et al., 2010) but there are some occasional situations where clouds are not detected or misclassified.

In the target classification, a lidar is used for the detection of liquid water clouds as it is very sensitive to the presence of liquid droplets. The first cloud layer will almost always be 
detected (caveat: fog layers, see below), including detection of thin supercooled liquid layers at significant altitudes, but the inherent disadvantage at lidar wavelengths is that the first liquid layer will also usually attenuate the lidar signal drastically; in multi-layered cases, subsequent layers are frequently not detected by the lidar. Detection of subsequent cloud layers relies primarily on their detection by cloud radar; however, liquid layers (in the absence of precipitation) are often close to the detection limit of cloud radars. If the air temperature is above freezing, any cloud layers detected by the radar are assumed to be liquid, but in the absence of lidar information it can be difficult to distinguish liquid droplets from insects (Clothiaux et al., 2000). This issue is mitigated by the use of cloud radars with polarisation capability like the AMF $95 \mathrm{GHz}$ cloud radar. Insects have a much higher linear depolarisation ratio (LDR) than spherical liquid water droplets and discrimination between the two is usually straightforward, except for close to the sensitivity limit, where the LDR signal is dominated by noise and can no longer be used. The radar reflectivity of supercooled liquid layers will often be dominated by the scattering from coexisting ice and it is difficult to determine their presence unambiguously from radar alone.

Liquid layers close to the surface, such as fog, can also pose problems for detection. Identifying the existence of a fog layer is usually possible, but capturing any information about its height extent is much more difficult. Fog frequently occurred in the Murg valley in the early morning hours, but as we omit situations with low solar zenith angles (see section 4) due to the influence of mountain ridges on radiation measurements, these situations should not influence our results.

\subsection{Thermodynamic profiles}

Vertical information on temperature, humidity and pressure primarily stems from temporally interpolated radiosonde ascents, which were performed every six hours during the nine-month measurement period. However, due to subsequent quality checks, some of the radiosonde data have been rejected. Radiosonde ascents that did not exceed $10 \mathrm{~km}$ height above the surface are also excluded from the analysis. The remaining radiosondes are vertically interpolated to the final height grid. If necessary, climatological data are used to extend the thermodynamical profiles up to a height of $30 \mathrm{~km}$. The vertically interpolated profiles are then temporally interpolated to the $30 \mathrm{~s}$ grid. When more than 12 hours lie between two valid radiosonde ascents, the hourly output of the operational COSMO-DE model, the operational NWP model of the German Weather Service, is linearly interpolated to describe the thermodynamic profile at a given point of time. Finally, the temperature of the lowest height level is set to the $2 \mathrm{~m}$ air temperature of the ARM surface meteorological instrumentation, which is available with a 1-minute resolution.

To account for temporal variations in atmospheric water vapour above the AMF and to correct the wellknown upper-tropospheric dry bias in RS92 radiosonde data (Vömel et al., 2007; Cady-Pereira et al., 2008), MWR measurements of the integrated water vapour (IWV) are used to scale the temporally interpolated humidity profile. The MWR IWV is either from the University of Cologne's HATPRO instrument or, if the HATPRO measurements are not available, from the AMF two-channel MWR.
HATPRO measures atmospheric brightness temperatures in the K-band $(22-32 \mathrm{GHz}, 7$ channels) and in the V-band (51-59 GHz, 7 channels). Due to modifications of the operation mode during the deployment, the temporal resolution of zenith measurements of the IWV and LWP varies between $1 \mathrm{~s}$ and several minutes. The temporal resolution of the LWP and IWV measured by the AMF two-channel (23.8 and $31.4 \mathrm{GHz}$ ) MWR is $20 \mathrm{~s}$. The primary restriction to the MWR data is that they can not be used when the instrument's radome is wet because of dew or rain. In this case, the atmospheric profile is discarded.

Since some MWR IWV measurements are not filtered correctly before and after rain events, they are compared to GPS IWV measurements, which are not affected by rain, to ensure that the MWR and GPS IWVs differ by not more than $3 \mathrm{~kg} \mathrm{~m}^{-2}$. If the IWV difference is above this threshold, the whole profile is rejected. If the MWR IWV is consistent with the GPS IWV, it is used to scale the humidity profile as follows. If the IWV of the derived humidity profile ( $\left.I W V_{\mathrm{PROF}}\right)$ is larger than the IWV of the MWR ( $\left.I W V_{\text {MWR }}\right)$, the humidity in each height is simply scaled with the factor $I W V_{\mathrm{MWR}} / I W V_{\mathrm{PROF}}$. However, for the case of a dry radiosonde relative to the MWR, a simple scaling of the humidity profile might lead to unrealistically high values of supersaturation with respect to water. Thus we followed the iterative approach by Mather et al. (2007). Here, the relative humidity is gradually increased by a uniform fraction of $100-R H(z)$, where $R H(z)$ is the relative humidity as a function of height. If $R H$ is $100 \%$ in a layer, the humidity in this layer is not increased any further. The humidity profile is varied in this way until the difference between $I W V_{\mathrm{MWR}}$ and $I W V_{\mathrm{PROF}}$ is less than $0.01 \mathrm{~kg} \mathrm{~m}^{-2}$.

\subsection{Cloud properties and their uncertainties}

If a level in the atmospheric column is classified as cloudy, the cloud liquid and/or cloud ice water content as well as the particle size have to be determined. Profiles of cloud liquid water content are derived using the radar reflectivity profiles together with the LWP measured by the MWR. The radar reflectivity profiles are taken from the Cloudnet categorization product and are already corrected for gaseous attenuation and also for liquid attenuation in the absence of rain or melting layers. The LWP of the MWR is again either from the University of Cologne's HATPRO instrument or, if the HATPRO measurements are not available, from the AMF two-channel MWR.

If an atmospheric column contains only pure water bins, i.e. no bins containing a water-ice mixture, the LWC of the corresponding radar bins is calculated using the Z-LWC relationship by Fox and Illingworth (1997), $Z=a L W C^{b}$, where the parameters $a$ and $b$ were empirically determined to be 0.012 and 1.16, respectively. The MWR LWP is then used to scale the LWC profile derived from the radar. If water and ice are coexisting in a bin, e.g. in the presence of melting ice or ice and supercooled droplets, the Z-LWC relationship cannot be applied. In this case, it is very difficult to separate the radar signal into the contribution from liquid water and the contribution from ice. This separation can be done for some cases using a detailed analysis of the Doppler spectrum (Shupe et al., 2004). For profiles containing such bins, here we simply distribute the MWR LWP evenly throughout all radar bins containing liquid water. Note that we assume particles in mixed or melting layers to be either liquid or 
solid; mixed-phase particles are not accounted for. To derive the effective cloud liquid radius, we follow the approach of Frisch et al. (1995) who assumed a log-normal cloud droplet distribution. Then, the modal radius of this distribution is calculated as

$$
r_{\mathrm{m}}=\left(\frac{3 L W C}{4 \pi \rho_{\mathrm{w}} N_{\mathrm{D}} \exp \left(9 / 2 \sigma_{x}^{2}\right)}\right)^{1 / 3}
$$

where $\rho_{\mathrm{w}}$ is the density of water, $\sigma_{x}$ the logarithmic spread of the distribution and $N_{\mathrm{D}}$ the droplet concentration, which is assumed to be constant with height. Summarizing the results of various in situ measurements, Miles et al. (2000) found typical values of $N_{\mathrm{D}}=288 \mathrm{~cm}^{-3}$ and $\sigma_{x}=0.38$ for continental stratus and stratocumulus clouds with standard deviations of $159 \mathrm{~cm}^{-3}$ and 0.14 , respectively. Furthermore, the $k$ th moment of the distribution is

$$
\left\langle r^{k}\right\rangle=r_{\mathrm{m}}^{k} \exp \left(\frac{k^{2}}{2} \sigma_{x}^{2}\right) .
$$

Since the effective radius is defined as the third moment divided by the second moment, it is related to the modal radius by

$$
r_{\mathrm{eff}, \mathrm{liq}}=r_{\mathrm{m}} \exp \left(\frac{5}{2} \sigma_{x}^{2}\right)
$$

for a log-normal drop size distribution.

For ice clouds, the Cloudnet IWC product according to Hogan et al. (2006) is used. The IWC has been derived using an empirical formula based on aircraft measurements which relates IWC to radar reflectivity and temperature $T$. The most reliable retrieval of IWC is during periods without water clouds or rain. If a water cloud exists below the ice cloud, the radar reflectivity is corrected for attenuation using the MWR LWP. IWC information is not reliable or available if the radar signal is uncorrected due to missing MWR data, if the ice cloud has only been detected by the lidar, or if rain is present in the atmospheric column. Atmospheric profiles which are affected by these issues are discarded. The effective cloud ice radius is calculated following Ivanova et al. (2001), who relate it to the temperature $T\left({ }^{\circ} \mathrm{C}\right)$ by

$$
r_{\text {eff }, \text { ice }}=(75.3+0.5895 T) / 2 \text {. }
$$

Uncertainties in the derived cloud properties may lead to large uncertainties in the calculated radiative fluxes and heating rates, and thus need to be quantified. Additionally to a baseline radiative transfer simulation, we performed sensitivity studies (section 4.3), for which one parameter, namely LWC, IWC, $r_{\text {eff,liq }}$ or $r_{\text {eff,ice, was systematically }}$ increased and decreased. For clouds including liquid water, the uncertainty of the measured LWP is considered taking into account that the uncertainty increases with increasing LWP in a nonlinear fashion. Based on retrieval simulations, the LWP uncertainty is determined to be $22 \mathrm{~g} \mathrm{~m}^{-2}$ for low LWP values and increases to $45 \mathrm{~g} \mathrm{~m}^{-2}$ at $500 \mathrm{~g} \mathrm{~m}^{-2}$. For profiles containing low LWP (less than $70 \mathrm{~g} \mathrm{~m}^{-2}$ ), we simply scale the LWC profile with the fraction $\left(L W P_{\mathrm{PROF}} \pm \Delta L W P\right) / L W P_{\mathrm{PROF}}$. If the LWP is less than $22 \mathrm{~g} \mathrm{~m}^{-2}$, a reduction of LWP given the uncertainties above would lead to negative LWP values. In this case, the new LWP is set to $0.01 \mathrm{~g} \mathrm{~m}^{-2}$. For larger LWP values, a simple scaling would lead to too-small individual LWC errors of about $10 \%$ only. Since LWC derived from radar/radiometer measurements shows uncertainties of $30 \%$ or larger (Löhnert et al., 2001; Ebell et al., 2010), the LWC is varied by $30 \%$ in cases with LWP $>70 \mathrm{~g} \mathrm{~m}^{-2}$. The effective radius of liquid clouds was varied by the larger of $25 \%$ or $1 \mu \mathrm{m}$, which represents a realistic uncertainty of this variable (cf. Figure 2 in Sengupta et al., 2003). For ice clouds, we comply with the uncertainties given in the Cloudnet IWC data, which exhibit a bias error of $0.923 \mathrm{~dB}$ and typical random error of $1.76 \mathrm{~dB}$. Combining these errors, uncertainties in IWC are between $-46 \%$ and $+85 \%$, which are of the same order of magnitude as reported in Hogan et al. (2006). The effective radius for ice clouds was varied by $-50 \%$ and $+100 \%$.

\subsection{Radiative transfer calculations}

The broadband radiative transfer simulations were performed with the Rapid Radiative Transfer Model for GCM applications (RRTMG) of the Atmospheric Environmental Research Inc. (Mlawer et al., 1997; Barker et al., 2003; Clough et al., 2005). The RRTMG utilizes the correlated-k approach whereby the gaseous absorption data are directly obtained from the line-by-line radiative transfer model (LBLRTM). Fluxes and heating rates are calculated over 14 contiguous bands in the short wave and 16 contiguous bands in the long wave. In order to account for multiple scattering, a two-stream algorithm after Oreopoulos and Barker (1999) is applied. The optical properties of water clouds, i.e. cloud optical thickness, single-scattering albedo and asymmetry parameter, are calculated for each spectral band according to the parametrization of $\mathrm{Hu}$ and Stamnes (1993). Corresponding properties of ice clouds are determined from the parametrization of Ebert and Curry (1992). In the RRTMG, sources for absorption in the long wave and for extinction in the short wave part of the spectrum are water vapour, carbon dioxide, ozone, methane, oxygen, nitrogen, aerosols, and Rayleigh scattering. For ozone, methane, oxygen and nitrogen, profiles of the US Standard Atmosphere have been applied in this study. Carbon dioxide is assumed to have a constant concentration of $380 \mathrm{ppm}$.

To account for the effect of aerosols, vertical profiles of aerosol optical thickness, single-scattering albedo and asymmetry parameter have to be included in the RRTMG. For some short periods in June, July and August 2007 during the COPS experiment, vertical aerosol information from Raman-lidar observations and from aircraft measurements are available. However, since these measurements are very sparse and therefore not representative of the nine-month measurement period, we used the measurements of the AMF multi-filter rotating shadowband radiometer (MFRSR), which was operated nearly continuously during the AMF deployment. The MFRSR measures the direct normal solar, diffuse hemispheric and total hemispheric solar irradiances for six different wavelength intervals with a data sampling of $20 \mathrm{~s}$. From these observations, the optical depth of the atmosphere at five wavelengths can be derived. Furthermore, in clear-sky situations, the aerosol optical depths (AODs) at these five wavelengths and subsequently the Angström exponent can be inferred. Together with the MFRSR-derived Ångström exponent, we calculated the corresponding AODs of the RRTMG mid-interval wavelengths via the Ångström relationship (Ångström, 1929). For the Black Forest site, information on the aerosol optical depth is available on 
76 days with daily median values of AOD at $550 \mathrm{~nm}$ ranging from 0.06 to 0.36 . Since the daily data availability strongly varies between a few minutes and several hours, it is difficult to include adequate temporal variations of AOD in the radiative transfer calculations. Thus, we assumed a constant AOD with a typical value of 0.16 at $550 \mathrm{~nm}$ for the entire time period and used an exponential weighting function for vertical scaling with a scaling height of about $1.3 \mathrm{~km}$. For the single-scattering albedo and the asymmetry parameter, we apply the values for urban aerosol, which were computed from the Optical Properties of Aerosols and Clouds (OPAC) database (Hess et al., 1998).

Since the RRTMG requires a direct and a diffuse short wave surface albedo for the ultraviolet/visible and nearinfrared band, we calculated these values from the measured upward and downward short wave fluxes at the surface and derived a parametrization for the direct albedo following the approach of Yang et al. (2008). Firstly, a monthly diffuse albedo was computed from those measurements for which the downward SW flux is dominated by the diffuse flux. Then values for the direct albedo were calculated from the measured SW flux components and the corresponding monthly diffuse albedo. In order to describe the dependence of the direct albedo on the diffuse albedo and on the cosine of the solar zenith angle (SZA), a polynomial function was fitted to the calculated direct albedo values for each month in order to reduce the noise in the individual values. Given the corresponding monthly diffuse albedo and the cosine of the SZA, we can define both albedo components well. However, this technique, which used the broadband measurements at the AMF site, is unable to derive a spectrally resolved albedo. For the radiative transfer calculations, we therefore assume the ultraviolet/visible band and near-infrared band albedos to be identical. A typical value for the derived diffuse albedo is 0.22 with small monthly variations of 0.01 . The direct albedo roughly varies between 0.2 at small and 0.3 at large SZA.

\subsection{Broadband flux measurements}

In order to evaluate the accuracy of the calculated radiative fluxes using the thermodynamic and cloud profiles from our sampling technique, results are compared to observations of the AMF broadband short wave and long wave sky radiometers (section 4). The observed data streams are available with a 1 minute time resolution. For the comparison, we used the downwelling short wave $(0.3-3 \mu \mathrm{m})$ global hemispheric irradiance measured by the AMF unshaded pyranometer and the downwelling long wave $(4-50 \mu \mathrm{m})$ hemispheric irradiance measured by the shaded pyrgeometer of the AMF. Uncertainties are reported to be $6 \%$ or $10 \mathrm{~W} \mathrm{~m}^{-2}$ for the pyranometer measurements and $2.5 \%$ or $4 \mathrm{~W} \mathrm{~m}^{-2}$ for the pyrgeometer observations.

In addition to the observed fluxes, we also use estimates of clear-sky short wave and long wave fluxes for the estimation of the CRE (section 4.3). The clear-sky estimates are part of the Radiative Flux Analysis product and are derived according to the techniques described in Long and Ackerman (2000) and Long and Turner (2008). The clear-sky fluxes are calculated by determining fit coefficients for a simple model on days that are hemispherically clear and then applying this model on days that are not hemispherically clear. The accuracy of the clear-sky estimate is in general within the measurement uncertainty of the instrument itself. The LW clear-sky estimates become less accurate if the interpolated humidity and temperature profiles across the day strongly deviate from the observed ones. Problematic situations in this respect are sharp temporal changes in humidity and temperature, which cannot be accounted for in the retrieval. However, Long and Turner (2008) showed for different ARM facility sites that differences between measured and estimated LW clear-sky fluxes are within $4 \mathrm{~W} \mathrm{~m}^{-2}$ for at least $70 \%$ of the time.

\section{Cloud statistics}

Accurate determination of significant cloud statistics for the AMF deployment depends on high data availability and quality. With in total 76883830 s Cloudnet profiles, an excellent coverage of $97 \%$ over the nine-month deployment period is given. This allows a robust description of the occurrence of clouds and of different cloud types. Except for the unusually dry April, the cloud frequency is larger than $60 \%$ in each month, with peaks in May (77\%) and November (86\%, Figure 2). In order to obtain a highquality dataset for our analysis of the interaction of clouds and radiation, it is necessary to apply the quality filters discussed in sections 2.2 and 2.3. Situations with rain are discarded since in these cases the wet radome of the MWR contaminates the measurements. During the nine-month measurement period rain has been detected by the AMF optical rain-gauge for $10.5 \%$ of the time. Other reasons to eliminate a profile are missing MWR data and Cloudnet IWC information. MWR information was not available for $21.8 \%$ of all Cloudnet profiles. In a further $10.7 \%$ of the time, MWR IWV was not consistent with the GPS measurements. Due to rain or uncorrected attenuation in Z, IWC information was not available in $23.7 \%$ of all cases, while ice was only detected by the lidar during $11.9 \%$ of the time. Note that a profile might be excluded for several reasons. On the one hand, the humidity and in cloudy cases also the LWC profile cannot be scaled with the MWR IWV and LWP, respectively, if MWR information is not available. On the other hand, if the MWR LWP is missing, the radar reflectivity cannot be corrected for liquid attenuation, and the derived IWC is not reliable. These quality filters yield a clean dataset (named the 'data sample') of 364850 profiles or $47 \%$ of the Cloudnet profiles. The data availability of the final data sample comprising a complete set of thermodynamic and cloud properties is highest for the late summer months (up to 58\%) and lowest in April due to the delayed set-up of some of the instruments (Figure 2).

\subsection{Cloud occurrence of different cloud types}

Since the phase of a cloud strongly affects the radiative fluxes, we refine our analysis by considering different cloud types. We distinguish water clouds (WC), ice clouds (IC) and mixed-phase clouds (MC), which can further occur as single- (SL) or multi-layer (ML) clouds. Clouds are categorized as multi-layer if cloud layers are separated by one or more height bins. In this scheme, pure water clouds with ice clouds above are assigned as multi-layer mixed clouds. Figure 3 gives an overview of the occurrence of the different cloud types between April and December 2007 for the AMF site for the Cloudnet and the data sample. The Cloudnet data reveal that clouds were present during $72 \%$ 


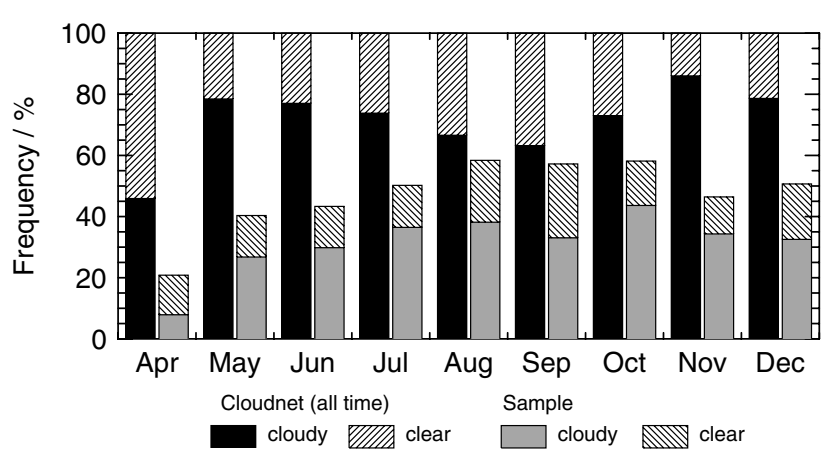

Figure 2. Data availability of Cloudnet data and data sample. The total number of Cloudnet profiles is 768 838. The data sample includes 364850 profiles. The frequency is given in \% relative to the total number of Cloudnet profiles.

of the time (Figure 3(a)). These clouds were mostly multilayer mixed clouds $(28.4 \%)$, followed by single-layer water (11.3\%), single- $(10.5 \%)$ and multi-layer ice $(10.2 \%)$ and single-layer mixed clouds $(9.4 \%)$. Multi-layer water clouds were only detected $2.3 \%$ of the time (although this may be an underestimate due to the attenuation of the lidar in the lowest liquid layer). Note that the partitioning into singlelayer and multi-layer clouds would slightly change if a less strict criterion for single-layer clouds were applied. If multilayer clouds were defined as clouds separated by two or more bins, for example, the percentage of multi-layer water clouds slightly decreases implying that the percentage of the corresponding single-layer cloud type likewise increases. In this case, the occurrence of multi-layer water, ice and mixed clouds is $1.7 \%, 8.1 \%$ and $25.7 \%$, respectively.

While the all-time and monthly occurrence of SL (Figure 3(c)) and ML water clouds are well represented in the data sample, the data availability of the other cloud types is significantly reduced. This is mainly caused by the better observing capabilities for lower clouds compared to higher clouds where radar and lidar can suffer from attenuation, preventing a quantitative analysis.

The observed vertical distributions of the different cloud types in the atmospheric column are shown in Figure 4. Most clouds occur between 1 and $3 \mathrm{~km}$ above MSL. Such clouds are present in about $22 \%$ of all profiles. Singleand multi-layer water clouds prevail in the lowest $2.5 \mathrm{~km}$ above the surface, while pure ice clouds dominate the cloud occurrence above $8 \mathrm{~km}$ MSL height.

\subsection{Cloud microphysical properties}

Before radiative transfer calculations are performed, we investigate the frequency distributions of LWC, IWC and $r_{\text {eff }}$ (Figure 5) derived using the technique described in section 2.2. Liquid water is primarily found in the lowest $3 \mathrm{~km}$. The median LWC sharply increases with height in the lowest $700 \mathrm{~m}$ resulting in a maximum median value with respect to all profiles of up to $0.035 \mathrm{~g} \mathrm{~m}^{-3}$. Above this height, the median LWC continuously decreases. The median LWC profile of SL WC only has a similar profile shape with a maximum value of about $0.053 \mathrm{~g} \mathrm{~m}^{-3}$. The median LWP of all profiles, including clear-sky situations, is $10.7 \mathrm{~g} \mathrm{~m}^{-2}$. If only cloud periods are considered, median LWP increases to $35.4 \mathrm{~g} \mathrm{~m}^{-2}$ for SL WC and $62.6 \mathrm{~g} \mathrm{~m}^{-2}$ for ML MC (Table I). If we use similar analysis techniques for other midlatitude but flat-terrain sites, namely the Cloudnet sites Lindenberg
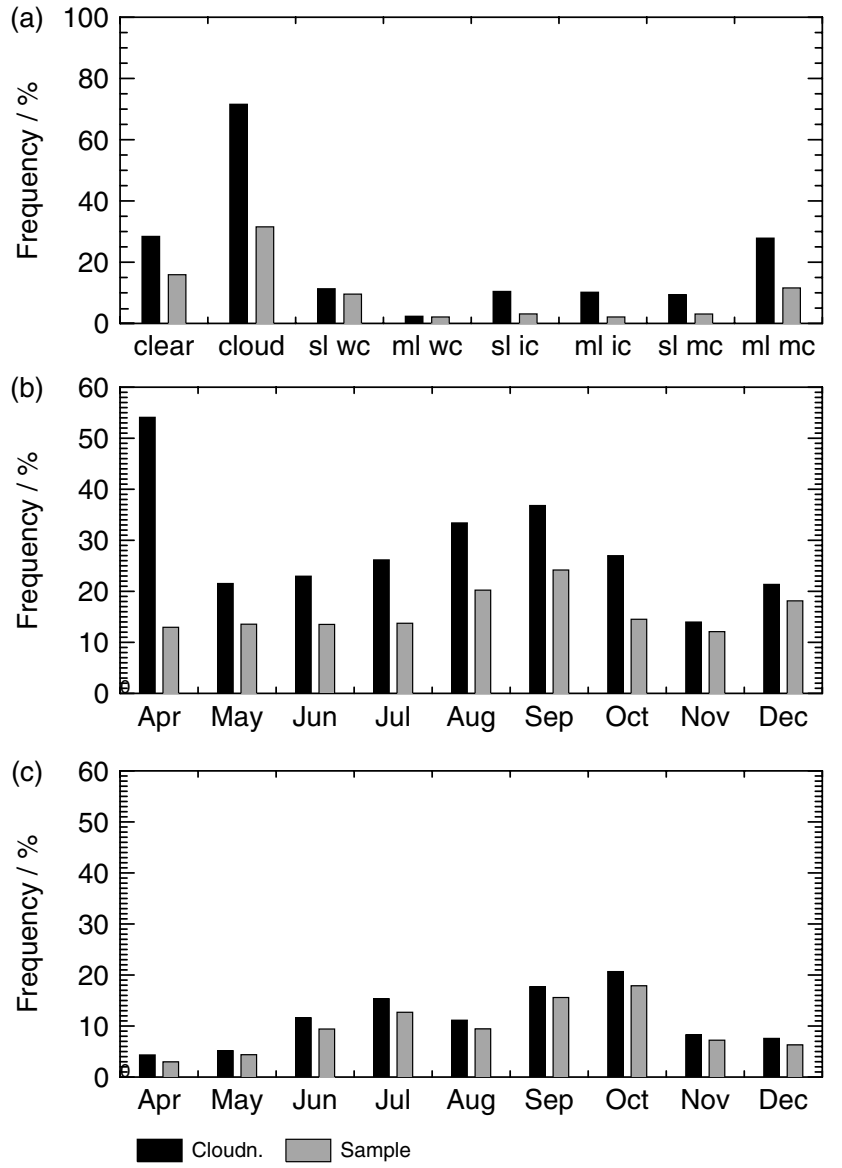

Figure 3. Cloud type frequency distributions of the Cloudnet categorization data and the final atmospheric dataset (data sample). The frequency is given in \% relative to the total number of Cloudnet profiles. (a) Frequency of different cloud types during the measurement period, single-layer (SL) and multi-layer (ML) water (WC), ice (IC) and mixed clouds (MC); (b) monthly clear-sky frequency; (c) monthly frequency of single-layer water clouds.

and Chilbolton, the LWP of SL WC in 2007 derived for the AMF site is also lower by about 5 and $14 \mathrm{~g} \mathrm{~m}^{-2}$, respectively.

Maximum IWC values are located in a height of about $5 \mathrm{~km}$ resulting in a median value of $0.003 \mathrm{~g} \mathrm{~m}^{-3}$ (Figure 5(b)). In the lower levels, the diagnosed IWC values span a wide range from less than $10^{-4}$ to $1 \mathrm{~g} \mathrm{~m}^{-3}$. Here, the IWC is primarily related to ice clouds detected in November and December. At higher altitudes, the cloud radar sensitivity is diminished, raising the threshold for the detection of small IWC values. This effect can be well observed at the left flank of the IWC distribution. On the other hand, IWC values greater than 0.1 are rare at high altitudes due to the reduction of available water. Therefore, between 6 and $11 \mathrm{~km}$, IWC values range from 0.001 to $0.01 \mathrm{~g} \mathrm{~m}^{-3}$. These heights also correspond to the maximum occurrence of SL and ML ice clouds, which have a median ice water path (IWP) of 7.1 and $10.9 \mathrm{~g} \mathrm{~m}^{-2}$, respectively. The shape and magnitude of the median and mean IWC profile is rather similar to those of the three Cloudnet sites Cabauw, Chilbolton and Palaiseau with maximum values around $5 \mathrm{~km}$ altitude (Illingworth et al., 2007).

Since the effective radius of liquid clouds is parametrized in terms of the LWC, the frequency distribution of $r_{\text {eff, liq }}$ is correlated with that of the LWC (Figure 5(c)). The largest values of the effective radius can be found in the lowest $3 \mathrm{~km}$ above the surface, whereby the most frequent values are between 2.5 and $10 \mu \mathrm{m}$. The range of the derived ice 

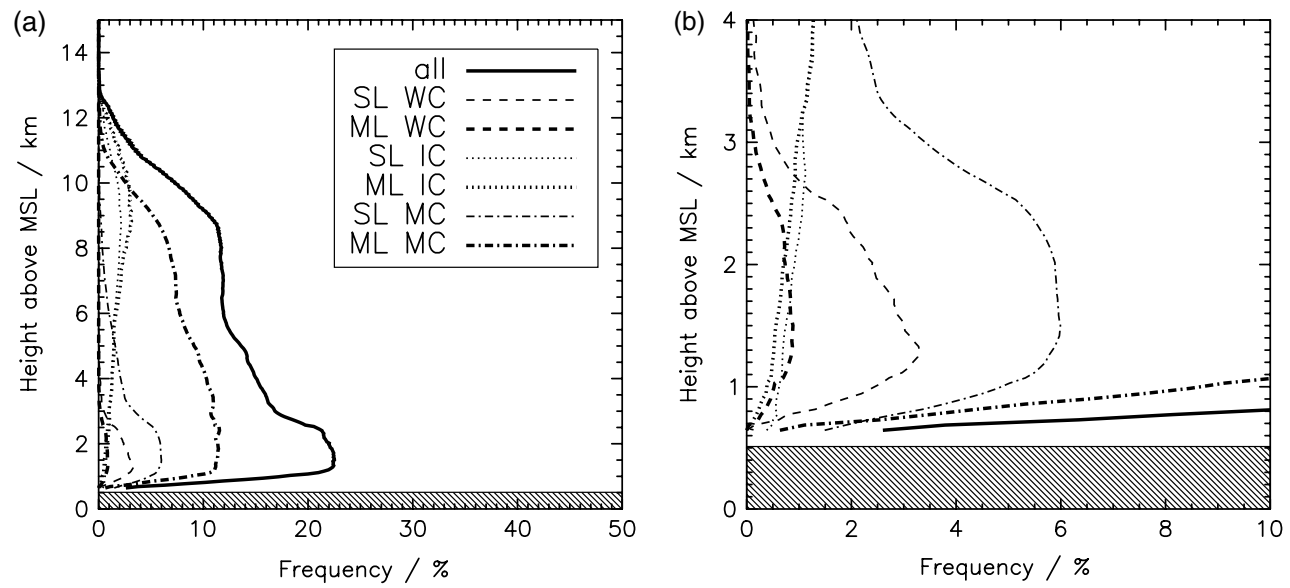

Figure 4. (a) Frequency distributions of different cloud types in the atmospheric column. Frequency is normalized by level. Cloud types are single-layer (SL) and multi-layer (ML) water (WC), ice (IC) and mixed clouds (MC). (b) shows an image detail of (a). The shaded area indicates the height of the AMF site (511 $\mathrm{m}$ above MSL).

Table I. Statistics of the different cloud types using the derived cloud property dataset

\begin{tabular}{|c|c|c|c|c|c|c|c|}
\hline & all clouds & SL WC & ML WC & SL IC & ML IC & SL MC & ML MC \\
\hline \multicolumn{8}{|l|}{30 s resolution } \\
\hline Number of profiles & 242555 & 73619 & 16151 & 23861 & 16157 & 23672 & 89090 \\
\hline Median LWP/gm ${ }^{-2}$ & 37.5 & 35.4 & 50.0 & - & - & 62.8 & 62.2 \\
\hline Median IWP/gm ${ }^{-2}$ & 0.1 & - & - & 7.1 & 10.9 & 0.5 & 2.4 \\
\hline Median $r_{\text {eff,liq }} / \mu \mathrm{m}$ & 5.3 & 5.4 & 4.9 & - & - & 5.5 & 5.3 \\
\hline Median $r_{\text {eff,ice }} / \mu \mathrm{m}$ & 31.1 & - & - & 29.1 & 29.0 & 35.3 & 31.2 \\
\hline Median cloud thickness/m & - & 343 & - & 1457 & - & 986 & - \\
\hline \multicolumn{8}{|l|}{5 min average, $\cos (S Z A)>0.3$} \\
\hline Number of profiles & 5871 & 1194 & 198 & 128 & 53 & 156 & 1757 \\
\hline Median LWP/gm ${ }^{-2}$ & 44.1 & 56.6 & 58.1 & - & - & 52.8 & 72.2 \\
\hline Median IWP/gm ${ }^{-2}$ & 4.6 & - & - & 11.4 & 14.8 & 1.5 & 6.2 \\
\hline Median $r_{\text {eff,liq }} / \mu \mathrm{m}$ & 5.4 & 5.8 & 5.0 & - & - & 5.0 & 5.6 \\
\hline Median $r_{\text {eff,ice }} / \mu \mathrm{m}$ & 30.4 & - & - & 27.8 & 29.4 & 34.9 & 30.4 \\
\hline Median cloud thickness/m & - & 429 & - & 1672 & - & 986 & - \\
\hline
\end{tabular}

Results are shown for the $30 \mathrm{~s}$ profiles and for 5 min averages used in the radiative transfer comparison. Cloud types are single-layer (SL) and multi-layer (ML) water (WC), ice (IC) and mixed clouds (MC).

effective radii is from $17 \mu \mathrm{m}$ at high altitudes to $40 \mu \mathrm{m}$ at low heights (Figure $5(\mathrm{~d})$ ). Since the ice effective radius is directly related to the temperature (Eq. (4)), the decrease of the temperature with height is reflected in the vertical distribution of $r_{\text {eff,ice }}$.

\section{Radiative transfer results}

Having established a comprehensive thermodynamic and cloud property dataset, we performed a radiative closure study over the full period of the AMF deployment. First, radiative transfer simulations are performed with RRTMG (section 2.4) using the derived atmospheric profiles as input data. Secondly, calculated fluxes at the surface are compared to the AMF measurements of the downwelling broadband long wave and short wave radiation fluxes. While the radiative transfer calculations are performed on the $30 \mathrm{~s}$ temporal grid defined for the atmospheric profiles, long wave and short wave fluxes are averaged over 5 minutes if not otherwise specified. This averaging procedure is needed to reduce the discrepancy due to the different fields-of-view of the instruments involved. While the cloud radar and the MWR, which are used to derive the cloud properties, measure only in a small solid angle around the zenith, the AMF broadband radiometers view the full hemisphere. Furthermore, we only consider those times for which the cosine of the SZA is greater than $0.3\left(\mathrm{SZA}<72.5^{\circ}\right)$. Since the AMF site was located in the Murg valley, the surrounding hills significantly affected the measured short wave fluxes during dusk and dawn. This shading can not be reproduced by the RRTMG which assumes a plane-parallel atmosphere and does not account for topographic effects and horizontal photon transport. In the next section, we present the results of the clear-sky flux comparisons (section 4.1), followed by the analysis of the radiative fluxes in cloudy situations (section 4.2). Finally, we focus on single-layer water clouds and assess their cloud radiative effect taking the uncertainty of the cloud parameters into account (section 4.3).

\subsection{Clear-sky flux comparisons}

In the following flux comparisons, all differences are presented in terms of calculated minus observed fluxes. The calculated and observed fluxes represent 5 minute averages. 

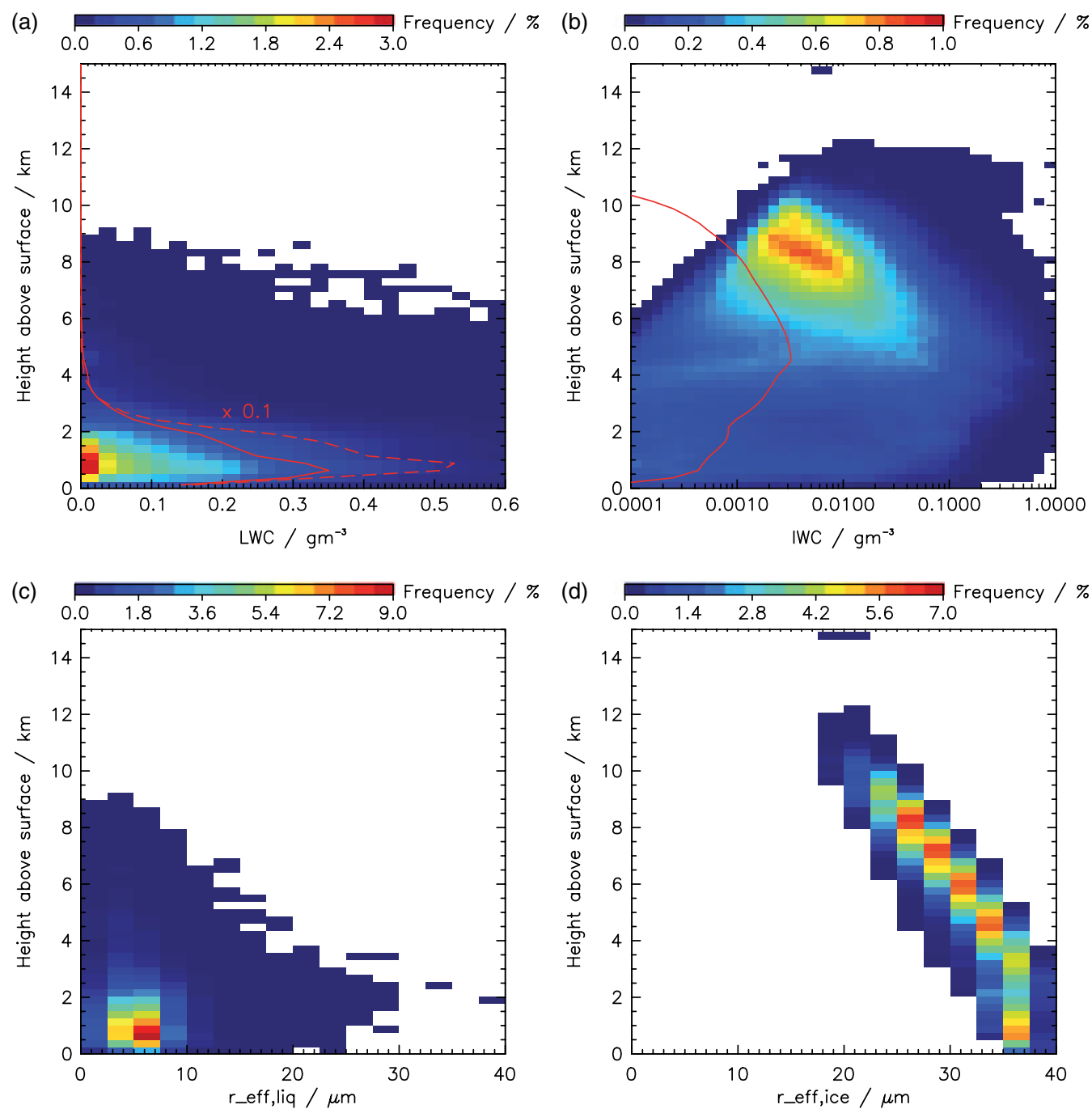

Figure 5. Frequency distribution of the derived microphysical cloud properties in the atmospheric column. Frequency is normalized by level. (a) Liquid water content (LWC, $\mathrm{g} \mathrm{m}^{-3}$ ); (b) ice water content (IWC, $\mathrm{g} \mathrm{m}^{-3}$ ); (c) cloud liquid effective radius $r_{\text {eff,liq }}(\mu \mathrm{m})$; (d) cloud ice effective radius $r_{\text {eff,ice }}(\mu \mathrm{m}$ ). The red solid lines indicate the median LWC and IWC profiles of all clouds, the dashed line the median LWC profile of all single-layer water clouds. The median LWC profiles are scaled by a factor of 10.

The modelled 5-minute averages are classified as clear-sky if all profiles within the 5 minutes are classified as cloud-free by the Cloudnet target categorization. The direct comparison of simulated with observed fluxes reveals a considerable scatter, but also a bulk of data points aligned along the one-to-one line (Figure 6). Bias and standard deviation are $33.6 \mathrm{~W} \mathrm{~m}^{-2}$ and $84.9 \mathrm{~W} \mathrm{~m}^{-2}$ in the short wave and $-15.6 \mathrm{~W} \mathrm{~m}^{-2}$ and $13.3 \mathrm{~W} \mathrm{~m}^{-2}$ in the long wave comparison (Table II). The overestimation in the downwelling SW and the underestimation in the downwelling LW flux are related to situations in which the hemisphere was actually not cloudfree. This can be seen if we employ a cloud flag derived from the radiation measurements (Long and Ackerman, 2000) and mark all times for which a cloud was detected during the 5 minute averaging interval (black asterisks in Figure 6(a) and (b)). Although categorized as cloud-free, clouds have been detected by the radiation measurements in $52 \%$ of the cases. Due to multiple-scattering effects at cloud boundaries, the SW downwelling radiation may even be underestimated in some cases. There are two reasons for these differences. Firstly, the classification may simply miss a cloud and the categorization procedure fails. Secondly, clouds are present but not directly located above the AMF site, and thus not in the narrow field of view of the cloud radar, lidar, or microwave radiometers. If the clear-sky flux statistics are calculated only for the subset of cases, when the hemisphere is cloud-free as indicated by the cloud flag, the results improve significantly, with small bias values and root-mean-squared (RMS) differences (Table II). Average differences are less than $2.1 \%$ and $3.9 \%$ for the short wave and long wave fluxes, respectively, and are in the same order of magnitude as in clear-sky comparisons of other studies (Mather et al., 2007; Dupont and Haffelin, 2008).

In order to assess the uncertainty in the downwelling fluxes due to uncertainties in the temperature, humidity and aerosol profiles, we performed sensitivity studies where one parameter has been subsequently changed. The humidity has been modified by $\pm 5 \%$ and the temperature profile by $\pm 1 \mathrm{~K}$. For the aerosol optical depth we assumed a value of $0.06(0.26)$ at $550 \mathrm{~nm}$, which represents a rough lower (upper) boundary value at the AMF site. The sensitivity tests revealed that in the SW part, the uncertainty in the downwelling fluxes is mainly determined by the uncertainty in the aerosol profile. A change of \pm 0.1 in AOD leads to a change in mean SW surface downwelling flux by more than $20 \mathrm{~W} \mathrm{~m}^{-2}$, explaining the bias of $7.4 \mathrm{~W} \mathrm{~m}^{-2}$. In addition, 
Table II. Comparison statistics of calculated and observed downwelling surface clear-sky fluxes

\begin{tabular}{|c|c|c|c|c|}
\hline \multirow[b]{2}{*}{$\mathrm{BIAS} / \mathrm{W} \mathrm{m}^{-2}$} & \multicolumn{2}{|c|}{ SW } & \multicolumn{2}{|c|}{ LW } \\
\hline & 33.6 & $(7.4)$ & -15.6 & $(-12.2)$ \\
\hline RMS difference/W $\mathrm{m}^{-2}$ & 91.3 & $(11.8)$ & 20.5 & $(13.5)$ \\
\hline STDDEV/W $\mathrm{m}^{-2}$ & 84.9 & $(9.3)$ & 13.2 & $(5.8)$ \\
\hline Average difference/\% & 17.9 & $(2.1)$ & 4.9 & $(3.9)$ \\
\hline Explained variance & 0.85 & $(1.00)$ & 0.86 & $(0.97)$ \\
\hline Slope of linear fit & 0.80 & $(0.99)$ & 0.85 & $(0.95)$ \\
\hline Intercept of linear fit & 135.7 & $(13.5)$ & 29.1 & $(2.5)$ \\
\hline
\end{tabular}

Statistics are calculated on the basis of 5 minute flux averages for times when the cosine of the solar zenith angle is larger than 0.3 (1734 values). The values in parentheses are the results for those times only when the Long cloud flag indicates clear-sky conditions (841 values). Differences are calculated minus observed fluxes.
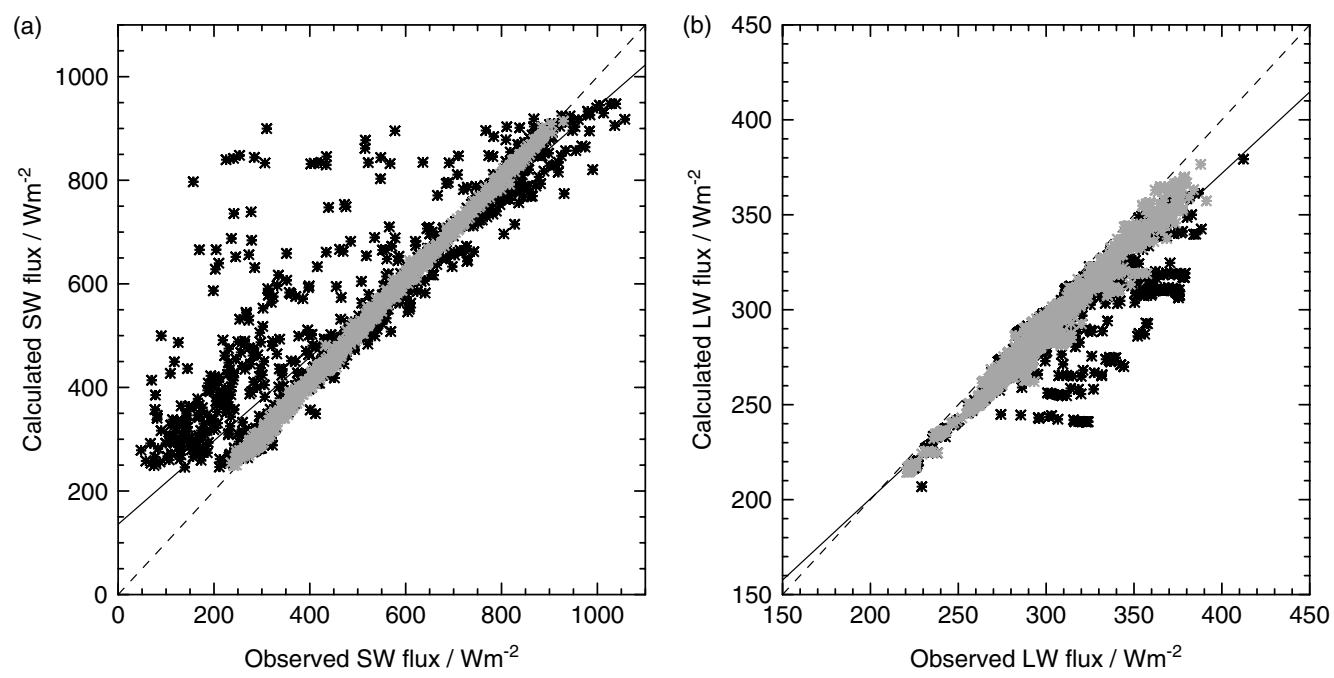

Figure 6. Clear-sky surface downwelling flux comparisons between calculated fluxes using the derived thermodynamic profiles and observed fluxes. Fluxes are 5-minute averages for times when the cosine of the solar zenith angle is larger then 0.3 (1734 values). Calculated fluxes are plotted against observed fluxes (a) in the short wave and (b) in the long wave. The black asterisks in (a) and (b) indicate the times when clouds have been detected by the radiation measurements but not by the Cloudnet categorization retrieval. The one-to-one line (dashed line) and the linear fit (solid line) are plotted for reference.

an underestimation of the humidity by $5 \%$ would lead to a positive SW bias of $1.4 \mathrm{~W} \mathrm{~m}^{-2}$. For the long wave fluxes, the temperature profile is especially important. An increase by $1 \mathrm{~K}$ causes a reduction in the $\mathrm{LW}$ bias by $4.7 \mathrm{~W} \mathrm{~m}^{-2}$. Keeping in mind that the temperature profile has been derived from temporal interpolation of 6-hourly radiosonde ascents or model output, differences in derived and actual temperature profiles may be several Kelvin. An underestimation of humidity by $5 \%$ would explain $-3.3 \mathrm{~W} \mathrm{~m}^{-2}$ of the negative LW bias. In general, the long wave flux at the surface is determined by both temperature and emissivity, which in turn depends on humidity. Therefore a temperature and humidity underestimation in our retrieval/interpolation largely explains the bias in the long wave fluxes. All in all, the agreement between the calculated and observed clear-sky surface fluxes is conclusive, especially with respect to the uncertainties in the input variables. Thus, the quality of the comparison confirms that the thermodynamic profile dataset is well suited for radiation studies.

\subsection{Cloudy-sky flux comparisons}

The comparison of the calculated and observed SW and LW surface fluxes is now extended to cloudy situations. Again, we compare 5 minute flux averages, except that we consider only those 5 minute averages in the analysis which were detected as being cloudy for $90 \%$ of the time. This constraint yields 5871 values corresponding to about $500 \mathrm{~h}$ of observations. For the moment, we do not distinguish different cloud types. Derived median values for LWP, IWP, $r_{\text {eff,liq }}$ and $r_{\text {eff,ice }}$ for this data sample are $44.1 \mathrm{~g} \mathrm{~m}^{-2}, 4.6 \mathrm{~g} \mathrm{~m}^{-2}$, $5.4 \mu \mathrm{m}$ and $30.4 \mu \mathrm{m}$ (Table I). Note that the LWP and IWV values are larger compared to the statistics based on the $30 \mathrm{~s}$ time interval.

For the SW downwelling fluxes, we find a significant scatter in the data (Figure $7(a)$ ) with a negative bias of $-38.2 \mathrm{~W} \mathrm{~m}^{-2}$ and a standard deviation of about $137 \mathrm{~W} \mathrm{~m}^{-2}$ (Table III). Observed values larger than $700 \mathrm{~W} \mathrm{~m}^{-2}$ are mostly related to broken cloud situations with a hemispheric cloud cover of $70 \%$ or less as derived from the AMF total sky imager (TSI). Due to the different sampling from the narrow field of view of the cloud radar, lidar and MWRs and the hemispheric irradiance measurements and due to the assumption of a plane-parallel atmosphere in the radiative transfer calculations, observed and modelled fluxes differ especially in broken-cloud situations. In order to assess the effect of horizontal cloud inhomogeneities and the corresponding three-dimensional (3D) scattering effects in the analysis, comparisons between observed and calculated fluxes are performed for different cloud cover thresholds 
using TSI measurements (Figure 7(c) and (d)). Restricting the analysis to situations with larger cloud cover values can significantly reduce the differences between calculated and observed values, but also reduces the size of the sample. Assuming a cloud cover of $90 \%$ or more, for example, reduces the number of values to 2651 or about 46 days but also results in a lower bias of $-13 \mathrm{~W} \mathrm{~m}^{-2}$ and in a lower standard deviation of about $83 \mathrm{~W} \mathrm{~m}^{-2}$. However, even for overcast situations, 3D scattering effects and inhomogeneities in the cloud field will still cause discrepancies between observed and modelled fluxes, so that these effects can never be completely separated from effects due to uncertainties in the cloud properties.

For the long wave part (Figure $7(\mathrm{~b})$ ), the results are much better than for SW, with a small, positive bias of $6.5 \mathrm{~W} \mathrm{~m}^{-2}$ and an RMS difference of $13.5 \mathrm{~W} \mathrm{~m}^{-2}$ (Table IV). The average difference is less than $3 \%$ and the explained variance 0.83. Broken clouds also have a strong effect on the LW fluxes (Figure 7(d)). Increasing the cloud cover threshold to $90 \%$, for example, reduces the standard deviation and the bias by $32 \%$ and $62 \%$ to $8.1 \mathrm{~W} \mathrm{~m}^{-2}$ and $2.5 \mathrm{~W} \mathrm{~m}^{-2}$, respectively.

We now investigate the effect of the different cloud types on the surface fluxes. A 5-minute average is attributed to a single cloud type if this cloud type occurs during $90 \%$ of the averaging time interval. For the different cloud types the median values for LWP and IWP and for the effective radii are listed in Table I. The results of the flux comparisons are given for the short wave and the long wave cases in Tables III and IV, respectively. In general, the performance in the SW region is worse than in the $\mathrm{LW}$, with a negative bias in the calculated fluxes of more than $30 \mathrm{~W} \mathrm{~m}^{-2}$ for all clouds containing liquid water, while pure ice clouds are nearly bias-free. A large part of the differences can be tracked down to broken cloud situations. If we relate each data point to the total cloud cover observation of the AMF total sky imager, it turns out that the pronounced over- and underestimation of the SW flux of single data members is again associated with cloud cover less than $70 \%$. If we consider, for example, only single-layer water clouds with cloud cover larger than $90 \%$, the bias reduces from $-9.1 \mathrm{~W} \mathrm{~m}^{-2}$ to $-9 \mathrm{~W} \mathrm{~m}^{-2}$ and the standard deviation from $138 \mathrm{~W} \mathrm{~m}^{-2}$ to $55 \mathrm{~W} \mathrm{~m}^{-2}$ (not shown). In the long wave part, the observed fluxes of all cloud types are well reproduced with an average difference of less than $3 \%$. Ice clouds show a negative bias of about $8 \mathrm{~W} \mathrm{~m}^{-2}$ while those clouds containing liquid water show a slight positive bias of $7 \mathrm{~W} \mathrm{~m}^{-2}$. The LW bias for ice clouds is consistent with the clear-sky bias and might be caused by a slight humidity underestimation (section 4.1).

Single-layer water clouds and multi-layer mixed clouds are the two most common cloud types in the dataset. Interestingly, we find that for the latter the performance in terms of average difference and explained variance for SW and LW is generally slightly better than those calculated for SL water clouds. This is most likely due to the fact that ML MC situations are often of stratiform nature and show a high optical thickness (higher LWP, Table I; low surface SW irradiance, Table III). It should be noted that the mixed clouds included in this study are dominated by the water phase. The median IWP of single- and multi-layer mixed clouds, namely $1.5 \mathrm{~g} \mathrm{~m}^{-2}$ and $6.2 \mathrm{~g} \mathrm{~m}^{-2}$, is smaller by one order of magnitude compared to SL and ML ice clouds. Single-layer and multi-layer mixed clouds with large
IWC are likely to precipitate and are therefore likely to be eliminated during the sampling of the atmospheric dataset.

In the following we focus on single-layer water clouds which would be intuitively judged as the simplest cloud type but reveal the strongest discrepancies in terms of radiation closure. The frequency distribution of SL WC LWP shows the typical decrease with increasing LWP (Figure 8(a)) with a median LWP of about $57 \mathrm{~g} \mathrm{~m}^{-2}$. The high number of low LWP profiles together with the typical LWP uncertainty of $\sim 20 \mathrm{~g} \mathrm{~m}^{-2}$ causes $18 \%$ of all profiles to exhibit errors of more than $100 \%$ in the LWP. Therefore, the detection of a water cloud from microwave LWP alone is difficult and is based here on the Cloudnet target categorization. Further, as part of the LWP uncertainty is attributable to retrieval ambiguities and instrumental drift, slowly changing LWP biases can occur which are most prominent during clear-sky periods. Different correction methods have been suggested (e.g. van Meijgaard and Crewell, 2005; Gaussiat et al., 2007; Turner et al., 2007a). The LWP of the HATPRO instrument, for example, was corrected for a local offset which was determined from all clear-sky LWP measurements within a $\pm 5 \mathrm{~h}$ window as described by van Meijgaard and Crewell (2005). The LWP of the AMF two-channel MWR was derived from a statistical retrieval where brightness temperature offsets were removed before the retrieval was performed (Turner et al., 2007a). This offset correction is based on clear-sky radiosonde observations and therefore on a similar time-scale as the bias correction for the HATPRO instrument.

The maximum occurrence of the cloud liquid effective radius of SL WC is in the range of 2.5 to $7.5 \mu \mathrm{m}$ with a median value of $5.8 \mu \mathrm{m}$ for $r_{\text {eff,liq }}$ (Figure $8(\mathrm{~b})$ ). Cloud thickness varies between $43 \mathrm{~m}$ and $2486 \mathrm{~m}$ (Figure 8(c)). Fifty per cent of the clouds show a thickness of less than $429 \mathrm{~m}$, typical of fair weather boundary layer clouds. In particular, these thin, broken clouds cause a considerable scatter between the observed and calculated fluxes (Figure 9). Again, the largest uncertainties in the SW fluxes are related to the representativeness of the 5 minute averages compared to the hemispheric flux measurements. As mentioned above, the bias of the calculated flux for SL water clouds can be significantly diminished, if we confine the data sample to almost overcast scenes (hemispheric cloud clover > 90\%). Overall, the results of the previous sections are encouraging. The results confirm that we can use the derived cloud profiles to evaluate the interaction of clouds and radiation, which will be discussed with respect to the cloud radiative effect of single-layer water clouds in the next subsection.

\subsection{Cloud radiative effect of single-layer water clouds}

Clouds generally lead to a negative SW and a positive LW CRE at the surface, whereby the CRE is defined as the difference between the cloudy and the clear-sky net radiative fluxes. At the surface, the effect of the clouds on the surface fluxes can be well quantified by the difference of the observed and clear-sky estimated fluxes without the need of radiative transfer calculations. In this way, the monthly mean surface CRE has been derived regardless of cloud type and for all observations over the nine-month period where $\cos (\mathrm{SZA})>0.3$ (Figure 10). During daytime periods the negative SW cloud radiative effect dominates the net cloud radiative effect, which is the sum of the SW and LW components. The variation in the solar insolation during 
Table III. Comparison statistics of calculated and observed surface short wave cloudy fluxes for different cloud types

\begin{tabular}{|c|c|c|c|c|c|c|c|}
\hline & all clouds & SL WC & ML WC & SL IC & ML IC & SL MC & ML MC \\
\hline Number of profiles & 5871 & 1194 & 198 & 128 & 53 & 156 & 1757 \\
\hline $\mathrm{BIAS} / \mathrm{W} \mathrm{m}^{-2}$ & -38.2 & -39.1 & -56.4 & 2.7 & 23.2 & -37.1 & -30.3 \\
\hline RMS difference/W $\mathrm{m}^{-2}$ & 141.8 & 143.1 & 153.3 & 124.2 & 155.5 & 119.7 & 101.4 \\
\hline STDDEV/W $\mathrm{m}^{-2}$ & 136.5 & 137.6 & 142.5 & 124.2 & 153.7 & 113.8 & 96.8 \\
\hline Average difference/\% & 32.7 & 35.7 & 26.7 & 37.6 & 60.7 & 33.2 & 28.7 \\
\hline Explained variance & 0.61 & 0.59 & 0.72 & 0.68 & 0.66 & 0.64 & 0.68 \\
\hline Slope of linear fit & 0.61 & 0.54 & 0.60 & 0.79 & 0.69 & 0.57 & 0.64 \\
\hline Intercept of linear fit & 70.1 & 78.8 & 74.5 & 93.4 & 154.2 & 59.5 & 47.1 \\
\hline Mean observed flux/ $\mathrm{Wm}^{-2}$ & 284.5 & 257.6 & 330.2 & 421.9 & 422.0 & 225.5 & 215.1 \\
\hline
\end{tabular}

Statistics are calculated on the basis of 5 minute flux averages for times when the cosine of the solar zenith angle is larger then 0.3 (5871 values). Differences are calculated minus observed fluxes. Cloud types are single-layer (SL) and multi-layer (ML) water (WC), ice (IC) and mixed clouds (MC).
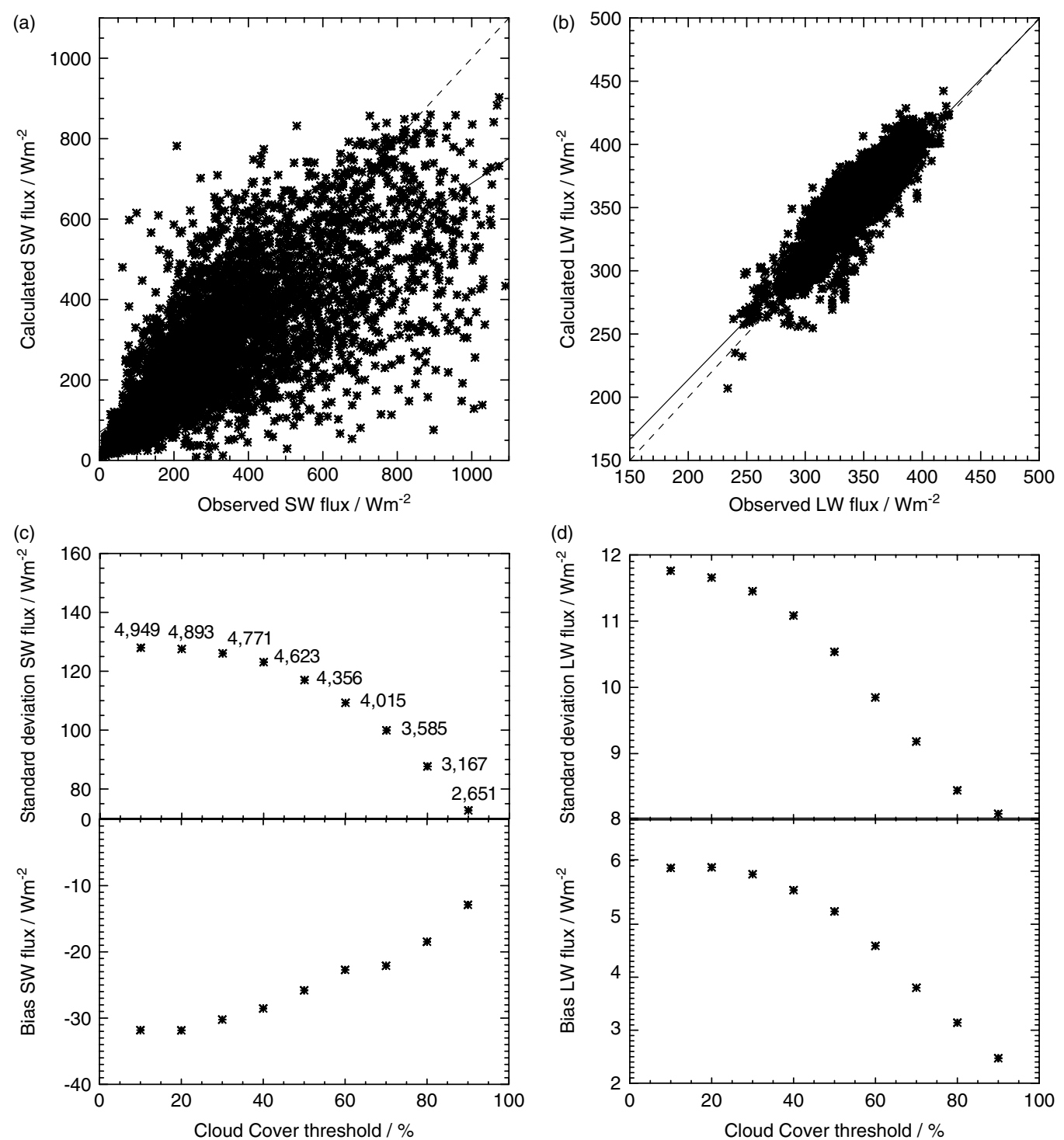

Figure 7. Cloudy surface downwelling flux comparisons between calculated fluxes using the derived thermodynamic and cloud microphysical profiles and observed fluxes. Fluxes are 5 minute averages for times when the cosine of the solar zenith angle is larger then 0.3. (a) Short wave flux; (b) long wave flux. The one-to-one line (dashed line) and the linear fit (solid line) are plotted for reference. The (c) SW and (d) LW standard deviation and bias are plotted against the cloud cover threshold. The numbers related to the data points in (c) are the same for the points in (d) and indicate the sample size. 
Table IV. Comparison statistics of calculated and observed long wave cloudy fluxes for different cloud types

\begin{tabular}{|c|c|c|c|c|c|c|c|}
\hline & all clouds & SL WC & ML WC & SL IC & ML IC & SL MC & ML MC \\
\hline Number of profiles & 5871 & 1194 & 198 & 128 & 53 & 156 & 1757 \\
\hline BIAS/W m $\mathrm{m}^{-2}$ & 6.5 & 7.7 & 7.2 & -8.4 & -7.7 & 5.5 & 7.4 \\
\hline RMS difference/ $\mathrm{W} \mathrm{m}^{-2}$ & 13.5 & 14.1 & 13.0 & 17.4 & 17.7 & 9.2 & 12.5 \\
\hline STDDEV/W $\mathrm{m}^{-2}$ & 11.9 & 11.8 & 10.8 & 15.2 & 15.9 & 7.3 & 10.0 \\
\hline Average difference/\% & 2.7 & 2.8 & 2.2 & 3.8 & 3.5 & 2.0 & 2.4 \\
\hline Explained variance & 0.83 & 0.83 & 0.74 & 0.70 & 0.77 & 0.96 & 0.85 \\
\hline Slope of linear fit & 0.95 & 0.87 & 0.98 & 0.93 & 0.81 & 0.96 & 0.93 \\
\hline Intercept of linear fit & 23.7 & 52.3 & 15.1 & 13.1 & 53.6 & 18.9 & 33.5 \\
\hline Mean observed flux/ $\mathrm{Wm}^{-2}$ & 351.4 & 348.8 & 369.8 & 328.4 & 330.6 & 325.7 & 354.5 \\
\hline
\end{tabular}

Statistics are calculated on the basis of 5 minute flux averages for times when the cosine of the solar zenith angle is larger then 0.3 (5871 values). Differences are calculated minus observed fluxes. Cloud types are single-layer (SL) and multi-layer (ML) water (WC), ice (IC) and mixed clouds $(\mathrm{MC})$.
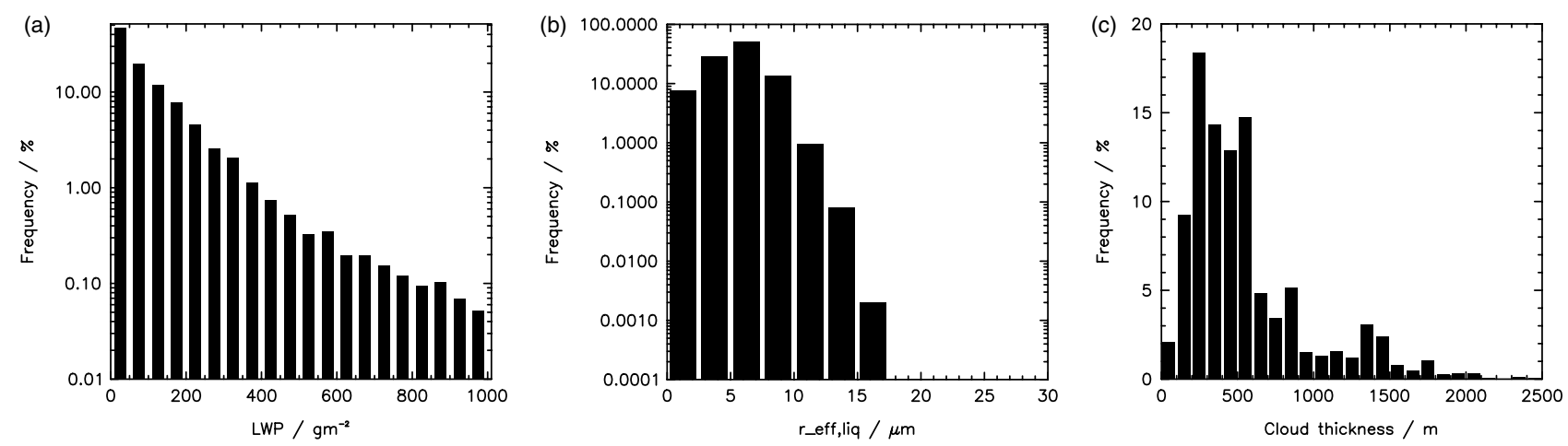

Figure 8. Frequency of the geometrical thickness and of the microphysical properties for single-layer water clouds. (a) LWP (g m ${ }^{-2}$ ); (b) cloud liquid effective radius $r_{\text {eff,liq }}(\mu \mathrm{m})$; (c) geometrical thickness $(\mathrm{m})$. Frequency is normalized by the total number of single-layer profiles.

the year is reflected in the monthly mean values of the SW SFC CRE with minimum values in the summer months and increasing values to the end of the year. In April, the SFC CRE is small for both LW and SW due to the prevailing cloud-free and thin cirrus conditions. In contrast to the SW CRE, the LW SFC CRE reveals much less variability with an almost constant monthly mean value of about $50 \mathrm{~W} \mathrm{~m}^{-2}$ from May to December. Note that if the whole day were considered, the higher weighting of the long wave effect would cause the net CRE to increase.

In addition to the SFC CRE, the radiative transfer simulations allow us to determine the CRE at the top of atmosphere (TOA), and to derive an atmospheric (ATM) cloud radiative effect, which is the difference between the TOA and SFC cloud radiative effects. In this section, we focus on the CRE of single-layer water clouds, which represent about $16 \%$ of the clouds, or the second most common cloud type by frequency, at the AMF site and are well represented by the derived data sample. Singlelayer water clouds are presumably less complex in their macrophysical and microphysical properties than other cloud types. However, uncertainties in LWC and effective radius also exist for these simpler clouds and will propagate to uncertainties of the radiative fluxes. Given the cloud microphysical profiles derived from the sampling method and their estimated uncertainties, as described in section 2.2 , we want to quantify the associated uncertainty of the CRE and the individual roles of LWC and effective radius. In addition to the baseline radiative flux calculation, we repeated the calculation with variations in LWC and $r_{\text {eff,liq. }}$ Since the surface radiation budget at the AMF site is strongly affected by the surrounding hills, it is not possible to determine a representative nine-month mean value of the CRE for the measurement site from the radiative transfer calculations. As in the previous sections, we only consider daytime periods when the cosine of SZA is larger than 0.3. We further restrict the analysis to almost overcast situations with a cloud cover larger than $90 \%$.

The mean CRE of single-layer water clouds during daytime periods $(\cos (\mathrm{SZA})>0.3)$ for SW and LW is summarized in Table $\mathrm{V}$ for the baseline and the sensitivity experiments. Single-layer water clouds have a net cooling effect on the climate system. The warming of the atmosphere due to absorption in the short wave part is overcompensated by atmospheric long wave cooling. The positive LW CRE at the surface and the TOA can only partly compensate the cooling effect in the corresponding SW components. These basic characteristics are not affected when varying the LWC and effective radius. However, the amount of cooling or heating can significantly change in the single components.

For the long wave part, changes in $r_{\text {eff,liq }}$ have only minor effects on the CRE, since the LW CRE is mainly influenced by the macrophysical properties of the cloud (vertical extension and position, which impact the cloud's temperature) and LWP. For the net CRE, changes in LWC result in variations of the TOA and SFC cloud radiative effect ( 8 to 19\%). An increase in LWC results in variations of the same order of magnitude as those due to an increase in effective radius. Variations in net TOA and SFC CRE due to a reduction of LWC are about twice as large as variations 

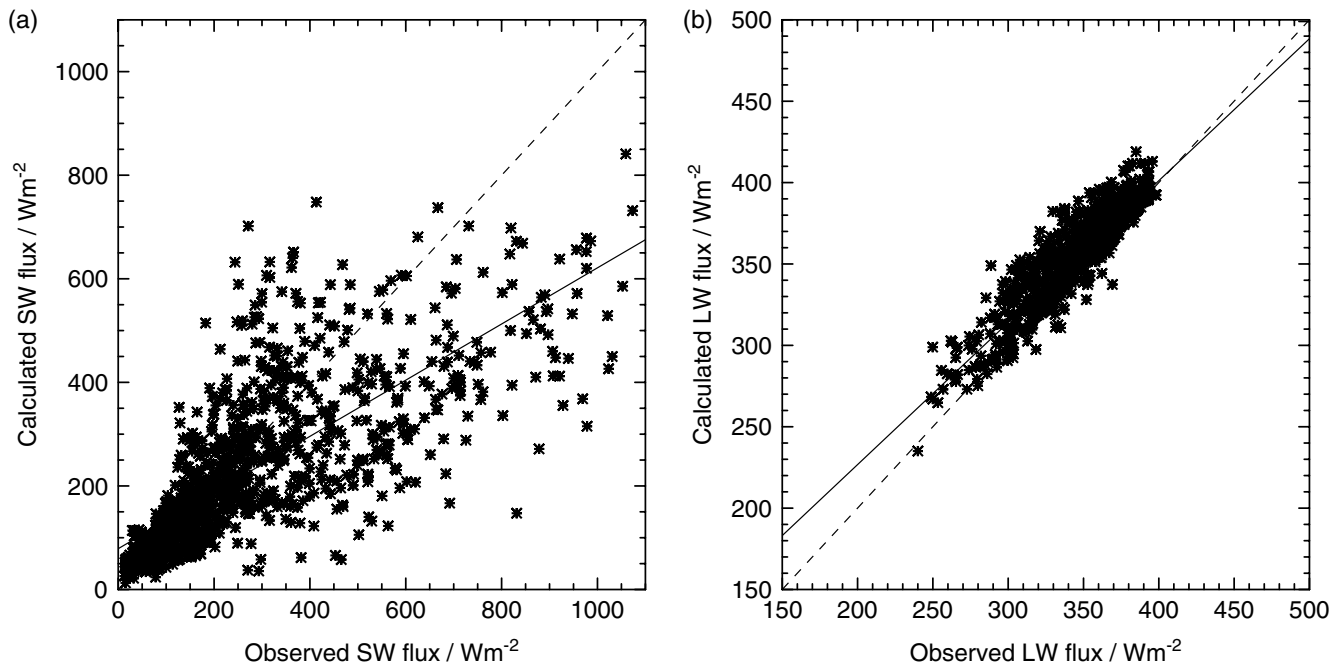

Figure 9. Comparisons between calculated and observed surface downwelling fluxes for single-layer water clouds. Fluxes are 5 minute averages for times when the cosine of the solar zenith angle is larger then 0.3 (1194 values). (a) Short wave flux; (b) long wave flux. The one-to-one line (dashed line) and the linear fit (solid line) are plotted for reference.

Table V. Mean cloud radiative effect of single-layer water clouds

\begin{tabular}{|c|c|c|c|c|c|}
\hline & baseline run & + LWC error & - LWC error & $+r_{\text {eff liq }}$ error & $-r_{\text {eff, liq }}$ error \\
\hline \multicolumn{6}{|l|}{$S W$} \\
\hline TOA & -246 & $-20(8)$ & $34(16)$ & $20(10)$ & $-24(9)$ \\
\hline ATM & 37 & $3(8)$ & $-5(15)$ & $0(1)$ & $-1(2)$ \\
\hline SFC & -283 & $-23(8)$ & $39(16)$ & $22(8)$ & $-23(8)$ \\
\hline \multicolumn{6}{|l|}{$L W$} \\
\hline TOA & 14 & $0(1)$ & $-1(8)$ & $0(0)$ & $0(0)$ \\
\hline ATM & -58 & $-1(1)$ & $4(7)$ & $0(0)$ & $0(0)$ \\
\hline SFC & 72 & $1(1)$ & $-5(7)$ & $0(0)$ & $0(0)$ \\
\hline \multicolumn{6}{|l|}{$\mathrm{Net}$} \\
\hline TOA & -231 & $-20(8)$ & $33(17)$ & $20(10)$ & $-24(9)$ \\
\hline ATM & -20 & $3(14)$ & $-1(6)$ & $0(2)$ & $-1(3)$ \\
\hline SFC & -211 & $-22(10)$ & 34 (19) & $20(10)$ & $-23(10)$ \\
\hline
\end{tabular}

The mean CRE is calculated on the basis of 5 minute flux averages for times when the cosine of the solar zenith angle is larger than 0.3 and the cloud cover larger than $90 \%$. The results for the sensitivity experiments are given as differences, i.e. new results minus results of the baseline simulation. The numbers in the brackets are the percentage changes with respect to the control run given in absolute values.

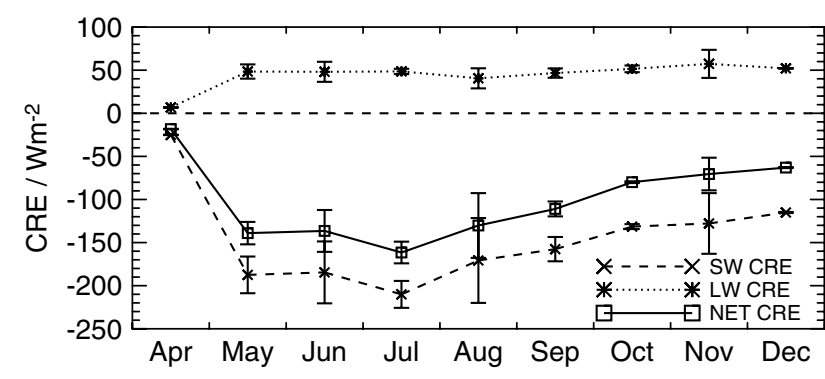

Figure 10. Monthly mean daytime $(\cos (\mathrm{SZA})>0.3)$ cloud radiative effect (CRE) calculated from the observed and clear-sky estimated surface fluxes. Short wave (dashed line), long wave (dotted line), and net CRE (solid line). The monthly mean values have been calculated from daily mean values, whose standard deviation is indicated by the vertical bars.

due to uncertainties in effective radius (about 10\%). As the LW and SW atmospheric CRE, the net atmospheric CRE is nearly insensitive to changes in $r_{\text {eff,liq }}$ and is more sensitive to changes in LWC, in particular to a reduction of this quantity.
For a better assessment of the influence of measurement uncertainties, the sensitivity of the short wave CRE for the TOA, ATM and SFC with respect to the LWP of the cloud is analysed (Figure 11). In general, short wave CRE at the surface is negative, since the downwelling radiation is significantly reduced compared to clear sky. Due to backscattering of solar radiation at cloud top, the upwelling short wave flux at the TOA is larger compared to clearsky situations, leading to a negative short wave CRE at the TOA. In most cases, the atmospheric cloud radiative effect is positive, since the absorption of solar radiation results in a heating of the atmosphere.

When LWP is low $\left(<70 \mathrm{~g} \mathrm{~m}^{-2}\right)$, small changes in this variable can lead to large variations of the surface short wave downwelling flux. Consequently, LWC and therefore LWP uncertainties in this range induce large uncertainties in the CRE at the surface of $100 \%$ or more. Similar uncertainties of the same order of magnitude can also be found at the TOA. When LWP increases and the cloud becomes more and more opaque, uncertainties in LWP play a minor role for the derived SFC and TOA cloud radiative effect (especially 

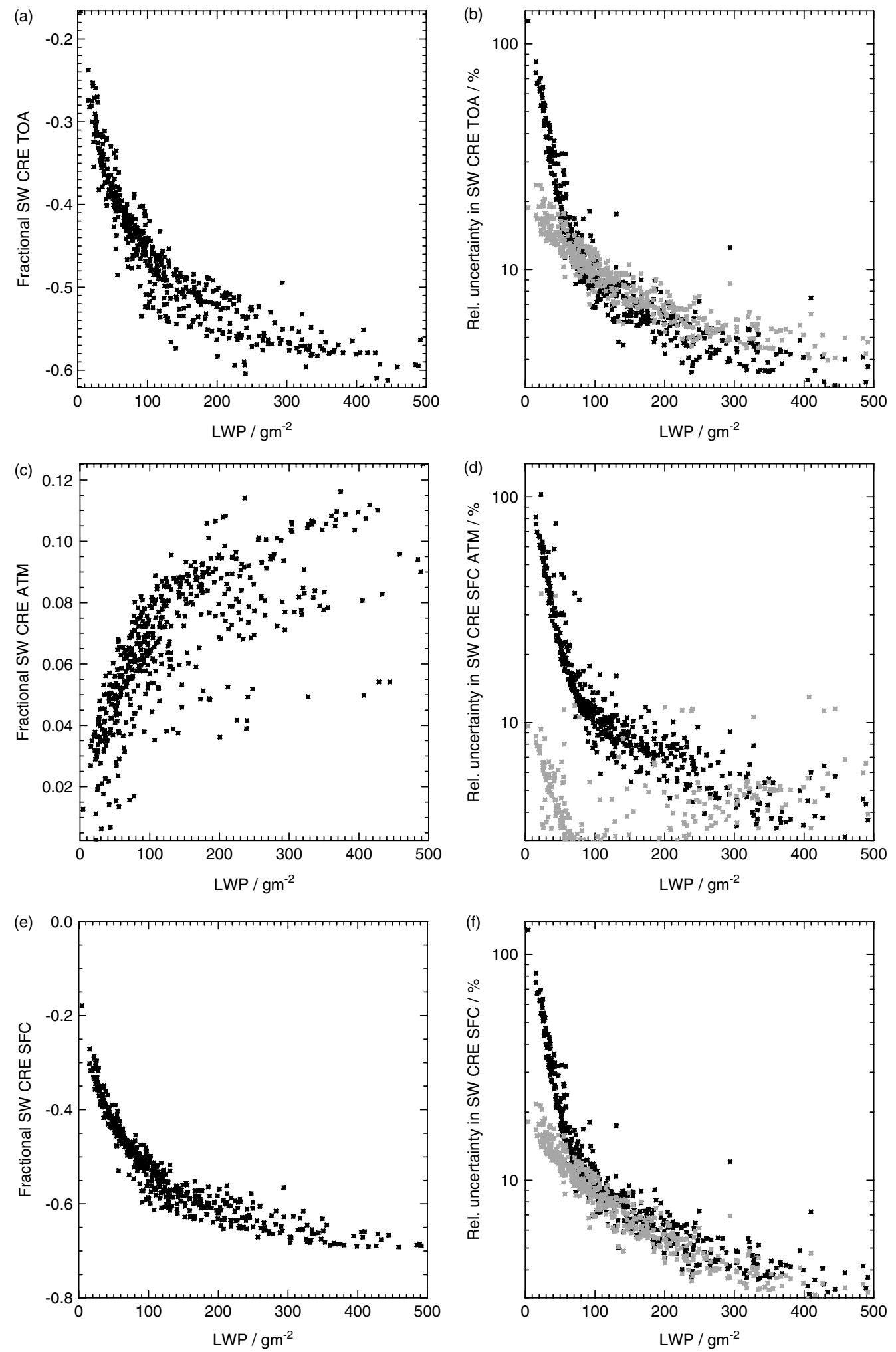

Figure 11. Short wave cloud radiative (CRE) effect of single-layer water clouds and its uncertainty. The CRE is calculated for 5 minute flux averages and only for times when the cosine of the solar zenith angle is larger than 0.3 and the cloud cover larger than $90 \%$. The CRE is normalized with the clear-sky downwelling flux at the surface and is plotted against the LWP of the cloud (left panels). Right panels: relative uncertainties in the CRE due to uncertainties in LWC (black asterisks) and in effective radius (grey asterisks). (a) and (b) CRE at the top of atmosphere (TOA); (c) and (d) atmospheric (ATM) CRE; (e) and (f) surface (SFC) CRE.

for the long wave flux). For variations in the effective radius, results are different. For liquid water paths less than $50 \mathrm{~g} \mathrm{~m}^{-2}$, the uncertainty in $r_{\text {eff, liq has a small effect on the accuracy }}$ of the derived CRE at the surface and TOA compared to the uncertainties related to LWP. For larger values, variations of CRE due to the uncertainty of the effective radius are roughly of the same order of magnitude as variations due to the LWC. For a cloud with an LWP of $100 \mathrm{~g} \mathrm{~m}^{-2}$, the variations in SFC and TOA short-wave CRE are approximately $10 \%$. As seen in Table V, when considering the atmospheric cloud radiative effect, the uncertainties in SFC and TOA CRE almost cancel each other for $r_{\text {eff,liq. }}$. 
Mace et al. (2006b) analysed the CRE at the ARM SGP site for the year 2000. They identified large uncertainties in the SW and net atmospheric CRE, namely 32 and 24\%, respectively, while in our study uncertainties are more pronounced at the SFC and TOA and partly compensated in the ATM CRE.

Sengupta et al. (2003) analysed the normalized cloud radiative flux (CRF) at the surface of continental stratus clouds. The normalized CRF is in this context the difference between the cloudy and clear-sky fluxes divided by the clearsky flux. Sengupta et al. (2003) found that the normalized cloud forcing is six times more sensitive to changes in LWP compared to changes in the effective radius given typical values of these variables over the SGP site. From these results, they concluded that the liquid water path is the dominant parameter for the determination of the solar transmission in continental stratus clouds. Our results have shown that the LWP is the dominant parameter for the SW surface CRE, and likewise for the normalized CRF, if the LWP is low. On the other hand, for LWP values larger than $50 \mathrm{~g} \mathrm{~m}^{-2}$, the accuracy of the effective radius significantly influences the accuracy of the SW CRE or the SW CRF at the surface. Unfortunately, accurate retrievals of LWP and $r_{\text {eff,liq }}$ are difficult for cloud cases where the LWP is small due to sensitivity issues of most instruments (e.g. Turner et al., 2007b). For LWP values larger than $100 \mathrm{~g} \mathrm{~m}^{-2}$, the uncertainty in CRE due to variations in $r_{\text {eff,liq }}$ is of the same order of magnitude as the uncertainty due to LWC variations. Therefore, for the determination of the SW surface CRE, the uncertainty in $r_{\text {eff, liq }}$ is in general not negligible.

\section{Summary and discussion}

High-quality thermodynamic and cloud property profiles have been derived for the nine-month measurement period of the ARM Mobile Facility in the Black Forest, Germany. The basis of the retrieval of these profiles is the Cloudnet target categorization product that provides information on the occurrence and the phase of the clouds. Furthermore, we combined measurements of various active and passive remote-sensing instruments with model and radiosonde information, as well as with simple cloud property retrieval algorithms, to derive thermodynamic profiles and, in the detected cloudy layers, cloud microphysical property profiles. Quality filters in the retrieval technique assure that the resulting profiles are reasonable and give the best estimate for the atmospheric state at this time. The derived dataset of atmospheric thermodynamic and cloud property profiles provides a valuable tool for numerous applications like the evaluation of NWP and climate models, the investigation of case-studies and the study of cloud-radiation interactions.

The 76883830 s Cloudnet profiles between April and December 2007 provide a solid statistic of the occurrence of clouds and of the cloud types over the AMF site. Except for April, cloud frequency is larger than $60 \%$ resulting in an overall cloud occurrence of $72 \%$. The most common clouds are multi-layer mixed and single-layer water clouds occurring $28.4 \%$ and $11.3 \%$ of the time, respectively. Singlelayer water clouds occur primarily in the lowest $2.5 \mathrm{~km}$ above the surface with a median thickness of $343 \mathrm{~m}$. Median effective radius and LWP are about $5.4 \mu \mathrm{m}$ and $35.4 \mathrm{~g} \mathrm{~m}^{-2}$, respectively. The LWP value found for the AMF site is lower than those found for the flat-terrain Cloudnet sites
Chilbolton $\left(49.6 \mathrm{~g} \mathrm{~m}^{-2}\right)$ and Lindenberg $\left(40.0 \mathrm{~g} \mathrm{~m}^{-2}\right)$ for the same time period. In this respect it is important to mention the representativity of column measurements for a site in orographic terrain. Scanning observations during a twomonth period in summer revealed higher $\left(10-20 \mathrm{~g} \mathrm{~m}^{-2}\right)$ LWP in the direction to the hill crests on both sides of the Murg valley.

In the sampling method of the thermodynamic and cloud profiles, quality checks are used to identify and remove profiles that exhibit the largest uncertainties due to missing or unreliable information on humidity, LWC and IWC. The resulting 'clean' 364850 profiles were evaluated by means of a long-term surface radiation closure study using independent measurements of short wave and long wave downwelling irradiances. For clear-sky situations as indicated by a cloud flag from radiation measurements (Long and Ackerman, 2000), the calculated surface fluxes agree very well with observed ones. Average differences are less than 2.1\% and $3.9 \%$ for the SW and LW fluxes, respectively. However, if the target classification is used as an indicator for the presence of cloud-free conditions, differences are significantly larger. In some of these cases, the classification simply misses a cloud, while in other situations a cloud was present but not directly located above the narrow field-of-view sensors (e.g. cloud radar) at the AMF site. This finding demonstrates the difficulty in comparing column results of the radiative transfer model to hemispheric observations.

The radiation comparison in cloudy conditions reveals a reasonable agreement of observed and calculated fluxes, with differences which are of the same order of magnitude as in the similar study by Mather et al. (2007) in a tropical region. In the $\mathrm{SW}$, a negative bias of $-38 \mathrm{~W} \mathrm{~m}^{-2}$ is present, while the calculated LW downwelling surface fluxes are on average too large by $7 \mathrm{~W} \mathrm{~m}^{-2}$. These biases may have several reasons. First, broken cloudiness has a strong impact on the results and complicates the comparison of calculated fluxes to hemispheric irradiance measurements. Due to the assumption of a plane-parallel atmosphere in the radiative transfer model, the calculated downwelling SW (LW) surface fluxes tend to be too small (large) compared to observed ones in broken cloud situations and thus yielding a negative (positive) SW (LW) bias. Restricting the analysis to more horizontally homogeneous cloud fields with cloud cover values larger than $90 \%$ can significantly reduce the RMS difference and the bias, but also the sample size. This reduction of the sample size may be especially problematic when the analysis focuses on specific cloud types.

Another reason for the negative SW and positive LW bias, which was also observed for single-layer water clouds, might be an overestimation of the cloud optical thickness. Since the cloud optical thickness is proportional to $L W P / r_{\text {eff,liq, }}$ an overestimation of cloud optical thickness in turn may be a result of an overestimation of LWP and/or of an underestimation of particle size. In the LW, the vertical distribution of liquid water within the cloud is also important: The LW downwelling flux at the surface primarily depends on the temperature of the lowest cloud layers. If the LWC had a positive bias or the effective radius had a negative bias in these cloud layers, then the opacity of these layers and therefore the downwelling LW flux would be overestimated. However, if the microphysical properties were the primary cause of the bias in the radiative fluxes, we would not expect a reduction of this quantity for higher cloud-cover thresholds. 
Although there is still potential to refine the retrieval of the atmospheric profiles, the results of the radiative closure studies are encouraging. However, uncertainties in the derived cloud properties exist and must be taken into account when evaluating the CRE. In this study, we focussed on single-layer water clouds, which are intuitively judged as the simplest cloud type, but reveal the strongest discrepancies in terms of radiation closure. Low-level clouds show the highest SW CRE (Chen et al., 2000) and have a net cooling effect on the climate system. For the SW and net CRE, changes in LWC result in variations of the TOA and SFC cloud radiative effect, which are on average twice as large as variations due to uncertainties in effective radius. As with the LW and SW atmospheric CRE, the net atmospheric CRE is nearly insensitive to changes in $r_{\text {eff,liq }}$ and is more sensitive to changes in LWC, in particular to a reduction of this quantity. For low LWP values, uncertainties in SW SFC and TOA CRE are dominated by the uncertainty in LWP, while for LWP values larger than $100 \mathrm{~g} \mathrm{~m}^{-2}$, the uncertainty in the CRE due to uncertainties in $r_{\text {eff, liq }}$ is of the same order of magnitude as the one related to the LWC.

\section{Outlook}

The dataset generated in this study has high value for atmospheric model evaluation and cloud-radiation studies. As a next step, we want to extend the analysis of the CRE to all cloud types and also aim at the vertical redistribution of energy by the clouds within the atmospheric column. As in this study, sensitivity experiments will be performed to support the results and to assess the potential uncertainty in the vertical heating rate structures.

In the future, improvements in the accuracy of the retrieved cloud property profiles may be realized by including more physically based retrieval techniques, like the Integrated Profiling Technique for LWC (IPT: Löhnert et al., 2008). The IPT combines measurements of MWR, cloud radar and radiosondes with a priori information in the framework of the optimal estimation technique (Rodgers, 2000). Since this technique accounts for measurement and forward model uncertainties, the uncertainty of the derived LWC profile is well defined. Thus, a more solid estimation of the uncertainty in the cloud radiative fluxes and heating rates is also possible. Uncertainties in LWP can also be reduced by including MWR measurements at higher frequencies (Crewell and Löhnert, 2003), typically at 90 and $150 \mathrm{GHz}$ available at the AMF from the Dual Polarization Radiometer of the University of Cologne, or by including infrared radiance observations, for example from the AMF Atmospheric Emitted Radiance Interferometer (AERI) instrument (Turner, 2007). Since the latter are very sensitive to changes in liquid water when LWP is small $\left(<50 \mathrm{~g} \mathrm{~m}^{-2}\right)$, the uncertainty of the derived LWP can be reduced in the LWP regime where SW surface fluxes and CRE are very sensitive to changes in this parameter. For thin clouds with low LWP values, the inclusion of spectral infrared information will not only improve the derived LWP but also liquid water effective radius (Turner, 2007). In order to increase the accuracy of the LWC profile, it is also planned to extend the IPT with the AERI observations. For the retrieval of temperature and humidity profiles in clear-sky cases, the potential of this combination of spectral microwave and infrared radiance observations has already been demonstrated (Löhnert et al., 2009).
A large fraction of the difference between the observed and calculated SW flux is caused by the broken cloud conditions, and the resulting $3 \mathrm{D}$ impacts on the radiative transfer that are not accounted for in the RRTMG. Fu et al. (2000), for example, have shown that photon leakage from the sides of the clouds can result in larger downwelling surface SW fluxes in full 3D radiative transport calculations compared to those using the independent column approximation (ICA). This underestimation of the ICA short-wave flux occurs at small solar zenith angles, while at larger ones the ICA overestimates downwelling solar surface flux compared to the $3 \mathrm{D}$ radiative transfer calculations, which account for interception and reflection of photons by cloud sides. Deneke et al. (2009) demonstrated for the AMF site that the 3D effect of clouds is also an important issue when comparing satellite and surface radiance measurements. Furthermore, their results indicate a higher spatial inhomogeneity in clouds at the AMF site compared to those at Cabauw. Therefore the dataset generated in this study is well suited, together with auxiliary information available on spatial cloud inhomogeneity (total sky imager, scanning MWR, satellite data), to investigate 3D effects in more detail.

A different radiative transfer model could be used to incorporate the $3 \mathrm{D}$ effects, but this requires that the $3 \mathrm{D}$ distribution of the clouds be quantified. One way to account for horizontal cloud variability or more precisely for horizontal variability in the LWP is to make use of the HATPRO measurements in the azimuth or 3D scanning modes (Kneifel et al., 2008), which are partly available during the AMF deployment. It is planned to test the potential of these measurements to further increase the skill of describing the radiative feedback of clouds. In the framework of the new Atmospheric System Research programme of the Department of Energy, the ARM measurement facilities will be provided with scanning cloud radars (US Department of Energy, Office of Science, 2010). Since these scanning systems can capture the spatial variability of the cloud field, they will provide valuable information for future cloud-radiation interaction studies.

\section{Acknowledgements}

Part of the work has been funded by the German Research Foundation within the priority programme SPP 1167 Quantitative Precipitation Forecast under grants CR 111/5-2 and WU356/4-2. Data were obtained from the Atmospheric Radiation Measurement (ARM) Program sponsored by the US Department of Energy, Office of Science, Office of Biological and Environmental Research, Environmental Sciences Division. The ARM program also supported the research efforts at the University of Wisconsin with grant DE-FG02-08ER64538. Clear-sky flux estimates are part of the Radiative Flux Analysis methodology which is a result of many years of research by Charles N. Long. We also thank Wenchieh Yen, who assisted in the realization of the radiative transfer simulations.

\section{References}

Ackerman TP, Stokes GM. 2003. The Atmospheric Radiation Measurement program. Phys. Today 56: 38-44.

Ångström A. 1929. On the atmospheric transmission of sun radiation and on dust in the air. Geograf. Ann. Deut. 11: 156-166.

Barker HW, Stephens GL, Partain PT, Bergman JW, Bonnel B, Campana K, Clothiaux EE, Clough SA, Cusack S, Delamere J, 
Edwards J, Evans KF, Fouquart Y, Freidenreich S, Galin V, Hou Y, Kato S, Li J, Mlawer EJ, Morcrette J-J, O’Hirok W, Räisänen P, Ramaswamy V, Ritter B, Rozanov E, Schlesinger M, Shibata K, Sporyshev P, Sun Z, Wendisch M, Wood N, Yang F. 2003. Assessing 1D atmospheric solar radiative transfer models: Interpretation and handling of unresolved clouds. J. Climate 16: 2676-2699.

Cady-Pereira KE, Shephard MW, Turner DD, Mlawer EJ, Clough SA, Wagner TJ. 2008. Improved daytime column-integrated precipitable water vapor from Vaisala radiosonde humidity sensors. J. Atmos. Oceanic Technol. 25: 873-883.

Chen T, Rossow WB, Zhang Y. 2000. Radiative effects of cloud-type variations. J. Climate 13: 264-286.

Clothiaux EE, Ackerman TP, Mace GG, Moran KP, Marchand RT, Miller MA, Martner BE. 2000. Objective determination of cloud heights and radar reflectivities using a combination of active remote sensors at the ARM CART sites. J. Appl. Meteorol. 39: 645-665.

Clough SA, Shephard MW, Mlawer EJ, Delamere JS, Iacono MJ, CadyPereira K, Boukabara S, Brown PD. 2005. Atmospheric radiative transfer modeling: A summary of the AER codes. J. Quant. Spectrosc. Radiat. Transfer 91: 233-244.

Crewell S, Löhnert U. 2003. Accuracy of cloud liquid water path from ground-based microwave radiometry. 2: Sensor accuracy and synergy. Radio Sci. 38: 8042, DOI: 10.1029/2002RS002634.

Deneke HM, Knap WH, Simmer C. 2009. Multiresolution analysis of the temporal variance and correlation of transmittance and reflectance of an atmospheric column. J. Geophys. Res. 114: D17206, DOI: 10.1029/2008JD011680.

Dong X, Minnis P, Xi B. 2005. A climatology of midlatitude continental clouds from ARM SGP central facility. Part I: Low-level cloud macrophysical, microphysical, and radiative properties. J. Climate 18: 1391-1410.

Dong X, Xi B, Minnis P. 2006. A climatology of midlatitude continental clouds from the ARM SGP central facility. Part II: Cloud fraction and surface radiative forcing. J. Climate 19: 1765-1783.

Dupont J-C, Haeffelin M. 2008. Observed instantaneous cirrus radiative effect on surface-level shortwave and longwave irradiances. J. Geophys. Res. 113: D21202, DOI: 10.1029/2008JD009838.

Ebell K, Löhnert U, Crewell S, Turner DD. 2010. On characterizing the error in a remotely sensed liquid water content profile. Atmos. Res. 96 : $57-68$.

Ebert EE, Curry JA. 1992. A parameterization of ice cloud optical properties for climate models. J. Geophys. Res. 97: 3831-3836.

Fox NI, Illingworth AJ. 1997. The retrieval of stratocumulus cloud properties by ground-based cloud radar. J. Appl. Meteorol. 36: 485-492.

Frisch AS, Fairall CW, Snider JB. 1995. Measurement of stratus cloud and drizzle parameters in ASTEX with a $\mathrm{K}_{\alpha}$-band Doppler radar and a microwave radiometer. J. Atmos. Sci. 52: 2788-2799.

Fu Q, Cribb MC, Barker HW, Krueger SK, Grossmann A. 2000. Cloud geometry effects on atmospheric solar absorption. J. Atmos. Sci. 57 $1156-1168$.

Gaussiat N, Hogan RJ, Illingworth AJ. 2007. Accurate liquid water path retrieval from low-cost microwave radiometers using additional information from a lidar ceilometer and operational forecast models. J. Atmos. Oceanic Technol. 24: 1562-1575.

Hess M, Koepke P, Schult I. 1998. Optical properties of aerosols and clouds: The software package OPAC. Bull. Am. Meteorol. Soc. 79 831-844.

Hogan RJ, Mittermaier MP, Illingworth AJ. 2006. The retrieval of ice water content from radar reflectivity factor and temperature and it use in evaluating a mesoscale model. J. Appl. Meteorol. Clim. 45 301-317.

Hogan RJ, O'Connor EJ, Illingworth AJ. 2009. Verification of cloudfraction forecasts. Q. J. R. Meteorol. Soc. 135: 1494-1511.

Hu YX, Stamnes K. 1993. An accurate parameterization of the radiative properties of water clouds suitable for use in climate models. J. Climate 6: $728-742$.

Illingworth AJ, Hogan RJ, O'Connor EJ, Bouniol D, Brooks ME, Delanoë J, Donovan DP, Eastment JD, Gaussiat N, Goddard JWF, Haeffelin M, Klein Baltink H, Krasnov OA, Pelon J, Piriou JM, Protat A, Russchenberg HWJ, Seifert A, Tompkins AM, van Zadelhoff G-J, Vinit F, Willén U, Wilson DR, Wrench CL. 2007. CLOUDNET continuous evaluation of cloud profiles in seven operational models using ground-based observations. Bull. Am. Meteorol. Soc. 88: 883-898.

IPCC. 2007. The scientific basis. Contribution of Working Group I to the Third Assessment Report of the Intergovernmental Panel on Climate Change. Cambridge University Press: Cambridge.

Ivanova D, Mitchell DL, Arnott WP, Poellot M. 2001. A GCM parameterization for bimodal size spectra and ice mass removal states in mid-latitude cirrus clouds. Atmos. Res. 59-60: 89-113.
Kneifel S, Crewell S, Löhnert U, Schween J. 2008. Investigating water vapor variability by ground-based microwave radiometry: Evaluation using airborne observations. IEEE Geosci. Remote Sensing Lett. 6: 157-161.

Löhnert U, Crewell S, Simmer C, Macke A. 2001. Profiling cloud liquid water by combining active and passive microwave measurements with cloud model statistics. J. Atmos. Oceanic Technol. 18: 1354-1366.

Löhnert U, Crewell S, Krasnov O, O'Connor EJ, Russchenberg H. 2008. Advances in continuously profiling the thermodynamic state of the boundary layer: Integration of measurements and methods. J. Atmos. Oceanic Technol. 25: 1251-1266.

Löhnert U, Turner DD, Crewell S. 2009. Ground-based temperature and humidity profiling using spectral infrared and microwave observations. Part I: Simulated retrieval performance in clear-sky conditions. J. Appl. Meteorol. Clim. 48: 1017-1032.

Long CN, Ackerman TP. 2000. Identification of clear skies from broadband pyranometer measurements and calculation of downwelling shortwave cloud effects. J. Geophys. Res. 105: 15609-15626.

Long CN, Turner DD. 2008. A method for continuous estimation of clear-sky downwelling longwave radiative flux developed using ARM surface measurements. J. Geophys. Res. 113: D18206, DOI: 10.1029/2008JD009936.

Mace GG, Benson S, Sonntag KL, Kato S, Min Q, Minnis P, Twohy CH, Poellot M, Dong X, Long CN, Zhang Q, Doelling DR. 2006a. Cloud radiative forcing at the Atmospheric Radiation Measurement program Climate Research Facility. 1: Technique, validation, and comparison to satellite-derived diagnostic quantities. J. Geophys. Res. 111: D11S90, DOI: 10.1029/2005JD005921.

Mace GG, Benson S, Kato S. 2006b. Cloud radiative forcing at the Atmospheric Radiation Measurement program Climate Research Facility. 2: Vertical redistribution of radiant energy by clouds. J. Geophys. Res. 111: D11S91, DOI: 10.1029/2005JD005922.

Mather JH, McFarlane SA. 2009. Cloud classes and radiative heating profiles at the Manus and Nauru Atmospheric Radiation Measurement (ARM) sites. J. Geophys. Res. 114: D19204, DOI: 10.1029/2009JD011703

Mather JH, McFarlane SA, Miller MA, Johnson KL. 2007. Cloud properties and associated radiative heating rates in the tropical western Pacific. J. Geophys. Res. 112: D05201, DOI: 10.1029/2006JD007555.

Miles NL, Verlinde J, Clothiaux EE. 2000. Cloud droplet size distributions in low-level stratiform clouds. J. Atmos. Sci. 57: 295-311.

Mlawer EJ, Traubman SJ, Brown PD, Iacono MJ, Clough SA. 1997. Radiative transfer for inhomogeneous atmospheres: RRTM, a validated correlated-k model for the longwave. J. Geophys. Res. 102: $16663-16682$.

Norris JR, Slingo A. 2009. Trends in observed cloudiness and Earth's radiation budget. Pp 17-36 in Clouds in the Perturbed Climate System, Heintzenberg J, Charlson RJ (eds). MIT Press: Cambridge, USA.

Oreopoulos L, Barker HW. 1999. Accounting for subgrid-scale cloud variability in a multi-layer $1 \mathrm{D}$ solar radiative transfer algorithm. Q. J. R. Meteorol. Soc. 125: 301-330.

Protat A, Delanoë J, Plana-Fattori A, May PT, O'Connor EJ. 2010. The statistical properties of tropical ice clouds generated by the West African and Australian monsoons, from ground-based radar-lidar observations. Q. J. R. Meteorol. Soc. 136(S1): 345-363.

Rodgers CD. 2000. Inverse Methods for Atmospheric Sounding: Theory and Practice. World Scientific.

Rose T, Crewell S, Löhnert U, Simmer C. 2005. A network suitable microwave radiometer for operational monitoring of the cloudy atmosphere. Atmos. Res. 75: 183-200.

Sengupta M, Clothiaux EE, Ackerman TP, Kato S, Min Q. 2003. Importance of accurate liquid water path for estimation of solar radiation in warm boundary layer clouds: An observational study. J. Climate 16: 2997-3009.

Shupe MD, Intrieri JM. 2004. Cloud radiative forcing of the Arctic surface: The influence of cloud properties, surface albedo, and solar zenith angle. J. Climate 17: 616-628.

Shupe MD, Kollias P, Matrosov SY, Schneider TL. 2004. Deriving mixedphase cloud properties from Doppler radar spectra. J. Atmos. Oceanic Technol. 21: 660-670.

Turner DD. 2007. Improved ground-based liquid water path retrievals using a combined infrared and microwave approach. J. Geophys. Res. 112: D15204, DOI: 10.1029/2007JD008530.

Turner DD, Clough SA, Liljegren JC, Clothiaux EE, Cady-Pereira KE, Gaustad KL. 2007a. Retrieving liquid water path and precipitable water vapor from Atmospheric Radiation Measurement (ARM) microwave radiometers. IEEE Trans. Geosci. Remote Sensing 45: 3680-3690.

Turner DD, Vogelmann AM, Austin RT, Barnard JC, Cady-Pereira K, Chiu JC, Clough SA, Flynn CJ, Khaiyer MM, Liljegren JC, Johnson K, 
Lin B, Long CN, Marshak A, Matrosov SY, McFarlane SA, Miller MA, Min Q, Minnis P, O'Hirok W, Wang Z, Wiscombe W. 2007b. Thin liquid water clouds: Their importance and our challenge. Bull. Am. Meteorol. Soc. 88: 177-190.

US Department of Energy, Office of Science. 2010. Atmospheric System Research (ASR) Science and Program Plan. http://www.sc.doe.gov/ober/Atmospheric System Research Science Plan.pdf. Online; accessed 23 February 2010, pp 77.

van Meijgaard E, Crewell S. 2005. Comparison of model predicted liquid water path with ground-based measurements during CLIWA-NET. Atmos. Res. 75: 201-226.

Vömel H, Selkirk H, Miloshevich L, Valverde-Canossa J, Valdés J, Kyrö E, Kivi R, Stolz W, Peng G, Diaz JA. 2007. Radiation dry bias of the Vaisala RS92 humidity sensor. J. Atmos. Oceanic Technol. 24: 953-963.

Willén U, Crewell S, Baltink HK, Sievers O. 2005. Assessing model predicted vertical cloud structure and cloud overlap with radar and lidar ceilometer observations for the Baltex Bridge Campaign of CLIWA-NET. Atmos. Res. 75: 227-255.

Wulfmeyer V, Behrendt A, Bauer H-S, Kottmeier C, Corsmeier U, Blyth A, Craig G, Schumann U, Hagen M, Crewell S, Di Girolamo P, Flamant C, Miller M, Montani A, Mobbs S, Richard E, Rotach MW, Arpagaus M, Russchenberg H, Schlüssel P, König M, Gärtner V, Steinacker R, Dorninger M, Turner DD, Weckwerth TM, Hense A, Simmer C. 2008. The Convective and Orographically induced Precipitation Study: A research and development project of the World Weather Research Program for improving quantitative precipitation forecasting in low-mountain regions. Bull. Amer. Meteorol. Soc. 89: $1477-1486$.

Wulfmeyer V, Behrendt A, Kottmeier C, Corsmeier U, Barthlott C, Craig G, Hagen M, Althausen D, Aoshima F, Bauer H-S, van Baelen J, Bennett L, Blyth A, Brandau C, Champollion C, Crewell S, Dick G, Dorninger M, Dufournet Y, Ehret G, Eigenmann R, Engelmann R, Flamant C, Foken T, Di Girolamo P, Groenemeijer P, Gorgas T, Grzeschik M, Handwerker J, Hauck C, Höller H, Junkermann W, Kalthoff N, Kiemle C, Klink S, König M, Koppert H-J, Krauss L, Long CN, Madonna F, Mobbs SD, Neininger B, Pal S, Peters G, Pigeon G, Radlach M, Richard E, Rotach MW, Russchenberg H, Schumann U, Schwitalla T, Simmer C, Smith V, Steinacker R, Trentmann J, Turner DD, Vogt S, Volkert H, Weckwerth T, Wernli H, Wieser A, Warrach K, Wunram C. 2011. The Convective and Orographically-induced Precipitation Study (COPS): The scientific strategy, the field phase, and research highlights. Q. J. R. Meteorol. Soc. 137(S1): 3-30, DOI: 10.1002/qj.752.

Yang F, Mitchell K, Hou Y-T, Dai Y, Zeng X, Wang Z, Liang XZ. 2008. Dependence of land surface albedo on solar zenith angle: Observations and model parameterization. J. Appl. Meteorol. Clim. 47: 2963-2982.

Zhang J, Lohmann U, Stier P. 2005. A microphysical parameterization for convective clouds in the ECHAM5 climate model: Single-column model results evaluated at the Oklahoma Atmospheric Radiation Measurement program site. J. Geophys. Res. 110: D15S07. DOI: 10.1029/2004JD005128. 